\title{
Nuclear Signaling of Plant MAPKs
}

\author{
Jean Bigeard ${ }^{1,2}$ and Heribert Hirt ${ }^{3 *}$ \\ ${ }^{1}$ Institute of Plant Sciences Paris-Saclay IPS2, Centre National de la Recherche Scientifique, Institut National de la \\ Recherche Agronomique, Université Paris-Sud, Université Evry, Université Paris-Saclay, Orsay, France, ${ }^{2}$ Institute of Plant \\ Sciences Paris-Saclay IPS2, Paris Diderot, Sorbonne Paris-Cité, Orsay, France, ${ }^{3}$ Center for Desert Agriculture, King Abdullah \\ University of Science and Technology, Thuwal, Saudi Arabia
}

\section{OPEN ACCESS}

Edited by:

Stéphane Bourque, Université de Bourgogne, France

Reviewed by:

Alok Krishna Sinha, National Institute of Plant Genome

Research, India

Olivier Lamotte,

INRA UMR1347 Agroécologie, France

*Correspondence: Heribert Hirt heribert.hirt@kaust.edu.sa

Specialty section: This article was submitted to Plant Physiology, a section of the journal Frontiers in Plant Science

Received: 06 December 2017 Accepted: 26 March 2018 Published: 11 April 2018

Citation:

Bigeard J and Hirt H (2018) Nuclear Signaling of Plant MAPKs.

Front. Plant Sci. 9:469. doi: $10.3389 / f p / s .2018 .00469$
Mitogen-activated protein kinases (MAPKs) are conserved protein kinases in eukaryotes that establish signaling modules where MAPK kinase kinases (MAPKKKs) activate MAPK kinases (MAPKKs) which in turn activate MAPKs. In plants, they are involved in the signaling of multiple environmental stresses and developmental programs. MAPKs phosphorylate their substrates and this post-translational modification (PTM) contributes to the regulation of proteins. PTMs may indeed modify the activity, subcellular localization, stability or trans-interactions of modified proteins. Plant MAPKs usually localize to the cytosol and/or nucleus, and in some instances they may also translocate from the cytosol to the nucleus. Upon the detection of environmental changes at the cell surface, MAPKs participate in the signal transduction to the nucleus, allowing an adequate transcriptional reprogramming. The identification of plant MAPK substrates largely contributed to a better understanding of the underlying signaling mechanisms. In this review, we highlight the nuclear signaling of plant MAPKs. We discuss the activation, regulation and activity of plant MAPKs, as well as their nuclear re-localization. We also describe and discuss known nuclear substrates of plant MAPKs in the context of biotic stress, abiotic stress and development and consider future research directions in the field of plant MAPKs.

Keywords: nucleus, mitogen-activated protein kinase, phosphorylation, signaling, biotic stress, abiotic stress, development

\section{INTRODUCTION}

In nature, plants constantly face changing conditions of both biotic and abiotic origin. To resist or tolerate these stresses, plants notably reprogram adequately the expression of their genes. This transcriptional reprogramming occurs downstream of a complex network of signaling pathways that is activated after signal perception at the cell surface. Understanding the signaling mechanisms allowing the transduction of the signal from the plasma membrane to the nucleus is an enormous challenge. This is especially true knowing the nucleus structure which includes a double membrane system that is punctuated by nuclear pores that allow the active transport or diffusion of molecules between the cytosolic and the nuclear compartments (Meier, 2007; Tamura and Hara-Nishimura, 2013). Diffusion into the nucleus is usually ineffective for molecules larger than $20-40 \mathrm{kDa}$ (Fried and Kutay, 2003).

Post-translational modifications (PTMs) constitute an important mechanism of protein regulation. Most PTMs are catalyzed by specific enzymes and are often reversible. They may activate/inhibit the activity of an enzyme, change the subcellular localization or stability of a protein and allow or prevent trans-interactions (Lothrop et al., 2013; Bigeard et al., 2014). Several hundred different PTMs have been reported and protein phosphorylation is probably the most abundant 
PTM found in eukaryotes (Khoury et al., 2011; Minguez et al., 2012; Olsen and Mann, 2013). Protein phosphorylation, mediated by protein kinases and removed by protein phosphatases, occurs predominantly on serine, threonine, and tyrosine residues. Plant genomes code for numerous protein kinases compared to other eukaryotes. For instance, about 1,000 and 1,400 genes are predicted to code for protein kinases in Arabidopsis thaliana (Arabidopsis) and Oryza sativa (rice), respectively, while the genomes of Homo sapiens and Saccharomyces cerevisiae code for about 500 and 120 protein kinases, respectively (The Arabidopsis-Genome-Initiative, 2000; Lander et al., 2001; Venter et al., 2001; Wang et al., 2003; Dardick et al., 2007). Among them, the mitogen-activated protein kinases (MAPKs) are conserved protein kinases among eukaryotes (Doczi et al., 2012; Lehti-Shiu and Shiu, 2012) and constitute signaling modules where MAPK kinase kinases (MAPKKKs) activate MAPK kinases (MAPKKs) which in turn activate MAPKs. In Arabidopsis, there are 20 MAPKs, 10 MAPKKs, and 60 MAPKKKs (MAPK-Group, 2002), and they are implicated in the signaling of multiple environmental stresses and developmental programs (Colcombet and Hirt, 2008; Rodriguez et al., 2010).

The identification of plant MAPK substrates is necessary to fully understand MAPK function and decipher the signaling mechanisms leading notably to the transcriptional reprogramming. Several hundred putative MAPK substrates have been identified via targeted experiments and more systematic approaches, such as phosphoproteomics and protein array screening (Feilner et al., 2005; Popescu et al., 2009; Hoehenwarter et al., 2013; Rayapuram et al., 2017). Among them, some were more extensively validated as MAPK targets, qualifying them as bona fide MAPK substrates. Actually, a large majority of the currently known bona fide plant MAPK substrates are transcription factors, indicating the preponderant involvement of plant MAPKs in nuclear signaling.

In this review, we first discuss the activation, regulation and activity of plant MAPKs, and their nuclear re-localization. We then present and discuss known nuclear substrates of plant MAPKs involved in biotic stress, abiotic stress and development, thereby putting forward the nuclear signaling of plant MAPKs. We finally discuss several highlights and unresolved questions regarding MAPK substrates and functions.

\section{MAPK ACTIVATION AND REGULATION}

Based on phylogenetic methods, plant MAPKs are divided into four groups (A to D) (MAPK-Group, 2002) and are characterized by the conserved TxY consensus motif in their activation loop (T-loop) which, when doubly phosphorylated by MAPKKs on the threonine and tyrosine residues, activate MAPKs (Anderson et al., 1990; Payne et al., 1991; MAPK-Group, 2002). Sequence comparison of this motif allowed classifying MAPKs into two subtypes: the TEY subtype gathers groups A, B, and C; the TDY subtype forms the more distant group D. Most MAPKs (groups $\mathrm{A}, \mathrm{B}$, and $\mathrm{C}$, but not group $\mathrm{D}$ ) also have a CD domain in their C-terminal region, which is a docking site for MAPKKs, MAPK phosphatases, and substrates, and corresponds to the amino acid sequence [LH][LHY]Dxx[DE] xx[DE]EPxC (Tanoue et al., 2000). On the other side, most MAPKKs, MAPK phosphatases and substrates have a putative MAPK docking site (D-site) which corresponds to the amino acid sequence $[\mathrm{K} / \mathrm{R}][\mathrm{K} / \mathrm{R}][\mathrm{K} / \mathrm{R}] \mathrm{x}(1-$ $5)[\mathrm{L} / \mathrm{I}] \mathrm{x}[\mathrm{L} / \mathrm{I}]$ and which binds the MAPK CD domain (Bardwell and Thorner, 1996; MAPK-Group, 2002; Bardwell, 2006).

Although the mechanism of plant MAPK activation is consensual, the kinetics of MAPK activation is variable and depends both on the upstream signaling events leading to MAPK activation and on the mechanisms of deactivation or turn-over of the MAPKs. For instance, the Arabidopsis MPK3, MPK4, MPK6, and MPK11 are activated by microbe-associated molecular patterns (MAMPs), such as the 22 amino acid long epitope flg22 from the $\mathrm{N}$ terminus of Pseudomonas aeruginosa flagellin (Gómez-Gómez and Boller, 2000), within 1 to 2 min leading to a peak of activity around 10-15 min which then rapidly decreases (Nuhse et al., 2000; Zipfel et al., 2006; Denoux et al., 2008; Ranf et al., 2011; Bethke et al., 2012; Frei Dit Frey et al., 2014). Besides, in the absence of MAMP-triggered immunity (MTI) but upon expression induction of a single effector, such as AvrRpt2 effector from Pseudomonas syringae, Arabidopsis MPK3 and MPK6 activation is detected at $3 \mathrm{~h}$ after induction and lasts for at least $7 \mathrm{~h}$ (Tsuda et al., 2013). Similar results are obtained when Arabidopsis leaves are infiltrated with $P$. syringae expressing AvrRpt2 (Underwood et al., 2007; Tsuda et al., 2013). As another example, the Arabidopsis MPK1 and MPK2 are activated by wounding with a peak around $2 \mathrm{~h}$ (Ortiz-Masia et al., 2007). As $\mathrm{H}_{2} \mathrm{O}_{2}$, jasmonic acid (JA) and abscisic acid (ABA) are involved in the wounding response, the authors also examined the effect of these molecules on MPK1 and MPK2 activity. The two MAPKs are activated by $5 \mathrm{mM} \mathrm{H}_{2} \mathrm{O}_{2}$ already after $15 \mathrm{~min}$ (first time point tested). Their results also show that $50 \mu \mathrm{M}$ JA induces the activation of the MAPKs already after $30 \mathrm{~min}$ (first time point tested) and their activity peaks in both cases at $1 \mathrm{~h}$ after treatment. Finally, $100 \mu \mathrm{M}$ ABA activates MPK1 and MPK2 already after 15 min (first time point tested), with a peak at $2 \mathrm{~h}$, and an activity which returns to basal levels by 8 h. Actually, Arabidopsis MPK7, which belongs to the group C MAPKs like MPK1 and MPK2, is also activated by ABA $(50 \mu \mathrm{M})$ with different time points tested showing a peak at $4 \mathrm{~h}$ (Danquah et al., 2015).

MAPK deactivation occurs via dephosphorylation of their activation loop by protein phosphatases (Lee and Ellis, 2007; Brock et al., 2010; Lumbreras et al., 2010; Umbrasaite et al., 2010; Galletti et al., 2011; Carrasco et al., 2014). These phosphatases belong to different families: protein tyrosine phosphatases (PTPs), serine/threonine phosphatases (PSTPs), and dualspecificity (Ser/Thr and Tyr) phosphatases (DSPs) (Andreasson and Ellis, 2010; Bartels et al., 2010). They are crucial because they regulate the intensity and duration of MAPK activation and thus their signaling output. For instance, we mentioned above the difference of activation of Arabidopsis MPK3 and MPK6 by MAMPs (transient activation with peak around $15 \mathrm{~min}$ ) and by pathogen effectors (activation for several hours). This difference of MAPK activation could be due to MAPK phosphatases which are active in MTI, rapidly dephosphorylating MAPKs, but 
inactive in effector-triggered immunity (ETI), resulting in the sustained activation of MAPKs (Tsuda et al., 2013). Interestingly, the abundance and activity of these phosphatases are often regulated by the MAPKs they dephosphorylate, thus forming a feed-back mechanism (Bartels et al., 2010; Park et al., 2011; González Besteiro and Ulm, 2013).

MAPK protein turn-over should also contribute to their kinetics of activation. However, this mechanism is scarcely documented, certainly because of the rapidity and efficiency of the phosphatase-dependent mechanism. For example, it was reported that Arabidopsis MPK3 and MPK6 abundance is downregulated at the protein level by the RAF-like MAPKKK EDR1 (Zhao et al., 2014).

\section{MAPK ACTIVITY AND MECHANISMS OF SPECIFICITY}

MAPKs are proline-directed serine/threonine kinases, meaning that the presence of a proline at position +1 of the phosphorylated site is required for substrate phosphorylation. Preferential positions of other amino acids were also observed, such as a proline at position -2 and a basic amino acid at position +2 (Berriri et al., 2012; Sorensson et al., 2012). The S/T$\mathrm{P}$ motif thus constitutes the minimal MAPK phosphorylation site motif, and indeed all MAPK protein substrates identified to date confirmed the requirement of this minimal motif. However, the $\mathrm{S} / \mathrm{T}-\mathrm{P}$ motif is present in about $80 \%$ of all proteins, indicating that other mechanisms are also necessary to select a given protein as a MAPK substrate (Bardwell, 2006).

The presence of MAPK docking motifs in proteins contributes to the specificity of MAPK substrates and most MAPK substrates indeed have a D-site for interaction with the MAPK CD domain. Generally, D-sites in MAPK substrates are located $<100$ amino acids upstream (N-terminal) from the MAPK phosphorylation site (Biondi and Nebreda, 2003; Ubersax and Ferrell, 2007). Besides D-sites, other docking motifs were also identified such as the amino acid sequence FxFP (DEF motif) and its variants, and the amino acid sequence LxxRR (Jacobs et al., 1999; Biondi and Nebreda, 2003; Sheridan et al., 2008). The combination of docking motifs may stabilize MAPK-substrate interactions and increase MAPK specificity and efficiency of phosphorylation.

In addition to docking motifs, MAPK specificity can also be brought about via adaptors or scaffolds which are proteins acting as organizing platforms that assemble the protein kinase and the substrate in the same complex (Zeke et al., 2009; Good et al., 2011). This mechanism is widely used in mammals and yeasts where notably scaffold proteins recruit the three kinases of MAPK modules (McDonald et al., 2000; Good et al., 2009; Zeke et al., 2009). Surprisingly, very few scaffold proteins have been identified to date in the context of plant MAPK signaling. The first clear plant MAPK scaffold is Arabidopsis RACK1 (Cheng et al., 2015). $P$. aeruginosa-secreted proteases activate a pathway involving heterotrimeric G-protein complexes and the MAPK module MEKK1-MKK4/MKK5-MPK3/MPK6. In this signaling pathway, RACK1 functions as a scaffold, binding to the $G \beta$ subunit of the heterotrimeric G-protein complex as well as to all three tiers of the MAPK module. Actually, MEKK1 was shown quite early to be able to interact with MKK1 and MKK2 but also MPK4 by yeast two-hybrid assays, suggesting that MEKK1 may be a scaffold protein (Ichimura et al., 1998). In addition, it was later shown that a kinase-impaired version of MEKK1, mutated in the ATP binding site (K361M), was able to rescue the mekk1 mutant dwarf phenotype, suggesting that MEKK1 would play a structural role that is independent of its protein kinase activity (Suarez-Rodriguez et al., 2007). This observation could reinforce a scaffold function for MEKK1. However, it is also possible that MEKK1 ${ }^{\mathrm{K} 361 \mathrm{M}}$ possesses a residual kinase activity that is sufficient to perform its normal functions, and there is still no evidence that MEKK1 and MPK4 can interact in planta. In tomato, the 14-3-3 protein TFT7 was also suggested to function as a scaffold because TFT7 can form a homodimer and it can interact with both the MAPKKK SIMAPKKK alpha and the MAPKK SIMKK2 (Oh and Martin, 2011). Similarly, the Arabidopsis transcription factor MYB44 is able to homodimerize and can interact with the nuclear sub-pools of both MKK4 and MPK3, suggesting that MYB44 could be a MAPK scaffold (Persak and Pitzschke, 2013).

Finally, co-expression and co-localization of MAPKs and their substrates in the same structures or subcellular compartments constitutes another way to regulate specificity (Kholodenko, 2006; Ubersax and Ferrell, 2007; Menges et al., 2008). The co-localization mechanism was shown notably for mammalian extracellular signal-regulated kinase (ERK) MAPKs (Robinson et al., 1998; Whitehurst et al., 2004). Dynamic nucleocytoplasmic shuttling of plant MAPKs is also observed (see the corresponding section below), probably contributing to specificity. For instance, the nucleocytoplasmic shuttling of mammalian ERK1 is slower than ERK2 and this mechanism significantly contributes to the differential capacity of ERK1 and ERK2 to produce signaling output (Marchi et al., 2008).

Substrate phosphorylation by protein kinases may have direct molecular effects and functional protein consequences. Phosphorylation may modify the global structure of a protein by conformational changes and may also alter interactions with other molecules (protein, DNA, RNA, etc.). For instance, the dual phosphorylation of the TxY motif changes the protein conformation of MAPKs rendering them active (Canagarajah et al., 1997), and the negative charge brought about by one or multiple phosphorylation events constitutes an interaction regulation mechanism (Cohen, 2000; Holmberg et al., 2002; Serber and Ferrell, 2007). These molecular changes may have multiple functional consequences. Phosphorylation may indeed activate or inhibit an enzyme activity, allow or prevent interaction between molecules, modify subcellular localization, or modify protein stability. To assess the functional roles of a phosphorylation event, the usual strategy consists in mutating the phosphorylated amino acid to a non-phosphorylatable amino acid (e.g., substitution of Ser to Ala) and/or to a phosphomimicking amino acid (e.g., substitution of Ser to Asp), and in expressing this mutated substrate in a knock-out line for the corresponding gene, ideally under the control of its own promoter. 


\section{FROM PUTATIVE TO GENUINE MAPK SUBSTRATES}

Usually, putative MAPK substrates are initially identified from systematic approaches, such as phosphoproteomics, protein array or yeast two-hybrid screening. However, much more evidence is necessary to qualify a protein as a genuine MAPK substrate.

At the biochemical level, the protein should be phosphorylated in vitro by the MAPK. This may be achieved for instance by a classical kinase assay using radiolabeled ATP or by a non-radioactive kinase assay followed by mass spectrometry analysis. Whatever the approach, the identification of the precise phosphorylation site(s) on the protein is required. A proof of the existence in planta of the phosphosite(s) identified in vitro is necessary as well. This proof may be found in databases such as PhosPhAt (Durek et al., 2010) that gather phosphoproteomic results, or a targeted experiment may be required to identify the phosphosite(s) in planta. An interaction in vivo between the protein and the MAPK should also be demonstrated. This may be achieved for example via bimolecular fluorescence complementation or by co-immunoprecipitation assays. Complementary approaches, showing the interaction between the protein kinase and its substrate can also be instructive, for instance by yeast two-hybrid or pull-down assays.

Genetically, it is expected that the protein phosphorylation disappears, or at least decreases in case of MAPK functional redundancy, in a mapk knock out line, and increases in a constitutively active or overexpressing MAPK mutant. We mentioned above the phospho-mutant versions of the candidate substrate (e.g., Ser to Ala and Ser to Asp phosphorylation site mutants). It may also be possible that these phosphosite mutant versions recapitulate the phenotype of the mapk knock out and/or the constitutively active or overexpressing MAPK mutant.

Overall, both biochemical and genetic evidence is thus required to designate a protein as a bona fide MAPK substrate, and obviously, several independent lines of evidence enhance the confidence for such an assumption.

\section{NUCLEAR LOCALIZATION OF MAPKs}

Only a small number of strictly nuclear protein kinases are known in plants in comparison to animals (Dahan et al., 2010). The majority of known nuclear plant protein kinases are indeed also localized in the cytosol. This is the case for the majority of plant MAPKs. The spatial organization of MAPKs, and more generally MAPK modules, and the signaling complexity was discussed elsewhere (Šamajová et al., 2012). Notably, the nuclear localization of MAPKs may be explained by the presence of nuclear sorting signals, i.e., nuclear localization signals (NLSs) or nuclear export signals (NESs), on the MAPKs themselves and/or on their substrates and regulatory proteins (e.g., activating MAPKKs and inactivating MAPK phosphatases) (Šamajová et al., 2012).

The first subcellular localization of plant MAPKs was determined in onion and pepper with the homologs of the tobacco NTF6 MAPK which displayed both a cytosolic and nuclear localization (Préstamo et al., 1999). Since then, the subcellular localization of a large number of MAPKs from different plant species was determined. In Arabidopsis, AtMPK3 is located in the cytosol, in the nucleus, and also associated to membranes (Ahlfors et al., 2004; Brock et al., 2010; Umbrasaite et al., 2010; Maldonado-Bonilla et al., 2013; Persak and Pitzschke, 2013; Pitzschke et al., 2014). AtMPK4 localizes to the cytosol, the nucleus, the plasma membrane, the cell plate and to microtubules (Schweighofer et al., 2007; Gao et al., 2008; Brock et al., 2010; Kosetsu et al., 2010; Umbrasaite et al., 2010; Beck et al., 2011). AtMPK6 was found in the cytosol, the nucleus, the plasma membrane, on mitotic microtubules and on secretory trans-Golgi network vesicles (Ahlfors et al., 2004; Schweighofer et al., 2007; Yoo et al., 2008; Brock et al., 2010; Muller et al., 2010; Umbrasaite et al., 2010; Maldonado-Bonilla et al., 2013; Persak and Pitzschke, 2013; Sethi et al., 2014). AtMPK3, AtMPK4, and AtMPK6 have been the most extensively studied Arabidopsis MAPKs, but some data also exist for other Arabidopsis MAPKs. For instance, AtMPK11 is located in both the nucleus and cytosol (Carrasco et al., 2014), and AtMPK12 is localized in both the nucleus and cytosol of guard cells (Jammes et al., 2009).

For the following plant species, we indicate in brackets the probable Arabidopsis orthologs of the cited MAPKs. In tobacco, the MAPKs NtWIPK (AtMPK3 ortholog), NtSIPK (AtMPK6 ortholog), NaMPK4 (AtMPK4/AtMPK11 ortholog), NTF4, and NTF6 all localize to both the nucleus and cytosol (Menke et al., 2005; Yap et al., 2005; Ishihama et al., 2011; Hettenhausen et al., 2012). In rice, OsMPK6 (AtMPK6 ortholog) is located only in the nucleus (Shen et al., 2010). Likewise, OsBWMK1 (AtMPK8/AtMPK9 ortholog) seems to localize exclusively to the nucleus (Cheong et al., 2003), however Koo et al. later reported that alternative splicing of OsBWMK1 generates three variants with different subcellular localizations: OsBWMK1Long and OsBWMK1Middle localize predominantly to the cytosol, while OsBWMK1Small primarily localizes in the nucleus (Koo et al., 2007). In cotton, GhMPK2 (AtMPK2 ortholog), GhMPK7 (AtMPK7/AtMPK14 ortholog), GhMPK11 (AtMPK4/AtMPK11 ortholog), and GhMPK16 (AtMPK16 ortholog) localize predominantly in the nucleus (Shi et al., 2010, 2011; Zhang et al., 2011; Wang et al., 2016), while GhMPK6a (AtMPK6 ortholog) and GhMPK20 (AtMPK20 ortholog) are present in both the cytosol and nucleus (Li et al., 2013; Wang et al., 2017). In canola, BnaMPK3, BnaMPK5, BnaMPK6, and BnaMPK9 (AtMPK3, AtMPK5, AtMPK6, and AtMPK9 ortholog, respectively) all localize in both the cytosol and nucleus (Liang et al., 2013). In maize, ZmMPK7 (AtMPK7/AtMPK14 ortholog) and ZmMPK17 (AtMPK15 ortholog) are located in the nucleus (Zong et al., 2009; Pan et al., 2012), while ZmMPK3 (AtMPK3 ortholog) is present in both the cytosol and nucleus (Wang et al., 2010). In wheat, TMPK3/WCK-1 (AtMPK3 ortholog) and TMPK6 (AtMPK6 ortholog) are present predominantly in the nucleus (Zaïdi et al., 2010). In Medicago species, alfalfa SIMK (AtMPK6 ortholog) locates predominantly in the nucleus (Munnik et al., 1999; Samaj et al., 2002; Ovecka et al., 2014), while MtMPK3 (AtMPK3 ortholog) and MtMPK6 (AtMPK6 ortholog) 
are localized in the cytosol, nucleus and to membranes (Chen et al., 2017; Ryu et al., 2017). In peanut, AhMPK3 (AtMPK3 ortholog) is located in both the cytosol and nucleus, while AhMPK6 (AtMPK6 ortholog) is present predominantly in the nucleus (Kumar et al., 2009; Kumar and Kirti, 2010). In soybean, GmMPK4a (AtMPK4 ortholog) is present in both the cytosol and the nucleus (Liu et al., 2011).

Overall, approximately one-third of the above cited plant MAPKs are only/predominantly localized in the nucleus, and two-thirds are present in both the cytosol and nucleus. Interestingly, probable MAPK orthologs do not seem to necessarily have the same subcellular localization, e.g., AtMPK6/NtSIPK/GhMPK6a/BnaMPK6/MtMPK6 localize in the cytosol and nucleus, while OsMPK6/TMPK6/SIMK/AhMPK6 are only nuclear. However, this apparent difference could also in part be due to technical differences, such as a lack of sensitivity of the approach or the use of heterologous expression systems.

It should also be noted that the nuclear localization of plant MAPKs is not limited to the MAPK level as some MAPKKs and MAPKKKs were also observed in this subcellular compartment. For instance, AtMKK4 is present in both the cytosol and nucleus (Yoo et al., 2008; Persak and Pitzschke, 2013), and AtMEKK1 was found in the cytosol, in the nucleus, at the plasma membrane and in vesicle-like structures (Miao et al., 2007; Gao et al., 2008; Yang et al., 2010).

\section{NUCLEAR RELOCALIZATION OF MAPKs}

The localization of most MAPKs in both the cytosol and nucleus suggests a regulation of nucleocytoplasmic shuttling. In particular, MAPK nuclear relocalization may occur upon some stimuli, strongly suggesting that the substrates of the protein kinase are only or mainly nuclear.

In the context of biotic stress, the parsley MAPK PcMPK3a translocates from the cytosol into the nucleus within 3-10 min after treatment with the fungal elicitor Pep25 (Ligterink et al., 1997). The same group later provided a more complete picture demonstrating that parsley PcMPK6, PcMPK3a, and PcMPK3b indeed rapidly translocate from the cytosol into the nucleus after Pep13 fungal elicitor treatment, but that parsley PcMPK4, which is not activated by the elicitor, remains cytosolic (Lee et al., 2004). Moreover, the authors did not observe a nuclear accumulation of PcMKK5, the upstream kinase of PcMPK6 and PcMPK3a/b, following Pep 13 treatment. In rice, OsBWMK1Long isoform, corresponding to the longest of the three existing splice variants, localizes predominantly in the cytosol and shuttles into the nucleus within $1-12 \mathrm{~h}$ after treatment with $2 \mathrm{mM}$ of the defense-related signaling molecules $\mathrm{H}_{2} \mathrm{O}_{2}$ and $\mathrm{SA}$ (Koo et al., 2007).

In the context of abiotic stress, the translocation of Arabidopsis AtMPK3 and AtMPK6 from the cytosol to the nucleus was observed after $30 \mathrm{~min}$ of ozone treatment (Ahlfors et al., 2004). Likewise, the peanut AhMPK3, which localizes in untreated conditions in both the cytosol and nucleus, was shown to predominantly translocate into the nucleus upon $10 \mathrm{mM} \mathrm{H}_{2} \mathrm{O}_{2}$ treatment for $60 \mathrm{~min}$ (Kumar et al., 2009). In soybean, GMK1
(AtMPK6 ortholog) is present in the cytosol under normal conditions and shuttles into the nucleus $60 \mathrm{~min}$ after $300 \mathrm{mM}$ $\mathrm{NaCl}$ treatment (Im et al., 2012). Interestingly, Ovecka et al. reported that in their inactive state alfalfa MAPKK SIMKK and MAPK SIMK (AtMPK6 ortholog) co-localize in the cytoplasm and in the nucleus and that upon 10-30 min of $250 \mathrm{mM}$ salt stress part of the nuclear pool of both SIMKK and SIMK relocates to cytoplasmic compartments (Ovecka et al., 2014). This result challenges the classical model of MAPK translocation from the cytosol to the nucleus upon activation.

In the context of development, the Arabidopsis BASL protein exhibits a polarized cellular localization pattern that is necessary for the differential cell fates resulting from asymmetric cell division in stomatal development. MPK6 phosphorylates BASL which is important for its polarization and function. In a positive feedback loop, BASL polarization then promotes the shuttling into the nucleus of more activated MPK6 molecules (Zhang et al., 2016). Plant MAPK translocation to the nucleus was also observed in pollen maturation (differentiation process) and in pollen embryogenesis (proliferation process) (Coronado et al., 2002).

Conversely, several studies also report MAPKs that do not exhibit a detectable relocalization upon stimuli yet known to activate them. For instance, the Arabidopsis MPK12 is present in both the cytosol and nucleus of guard cells, and is activated within minutes by $50 \mu \mathrm{M}$ ABA or $\mathrm{H}_{2} \mathrm{O}_{2}$ (Jammes et al., 2009). However, its subcellular localization is unaffected by $\mathrm{ABA}$ or $\mathrm{H}_{2} \mathrm{O}_{2}$ treatment, which suggests that MPK12 has substrates in both the cytosol and nucleus of guard cells.

We mentioned previously that the nuclear localization of plant MAPKs is not limited to the MAPK level as MAPKKs and MAPKKKs may also be present in the nucleus. This is true as well regarding nuclear relocalization upon stimulation. As an example, the Arabidopsis MKK9, which is upstream of MPK3 and MPK6 in ethylene signaling, shuttles into the nucleus in response to the ethylene biochemical precursor 1aminocyclopropane-1-carboxylic acid (ACC) (Yoo et al., 2008).

Figure 1 gives an overview of the different parts developed above. In the following sections, we discuss known nuclear substrates of plant MAPKs involved in biotic stress, abiotic stress and development. For more clarity, we organized subsections according to plant species. As the literature is too vast to discuss all reported plant MAPK substrates as part of this review, we selected a few tens (Table 1) that were extensively studied and that benefited from both biochemical and genetic evidence, qualifying them as bona fide MAPK substrates. We sincerely apologize to our colleagues whose work was thus not cited.

\section{BIOTIC STRESS}

\section{Arabidopsis MAPKs}

MPK4 has a dual role in defense and regulates defense responses downstream of multiple receptors. In the absence of a pathogen, it represses innate immunity genes, but upon pathogen attack, it is needed for the full induction of a large set of defense genes. Using yeast two-hybrid screening, Andreasson et al. (2005) identified MKS1 as an MPK4 substrate. MKS1 was shown to be 

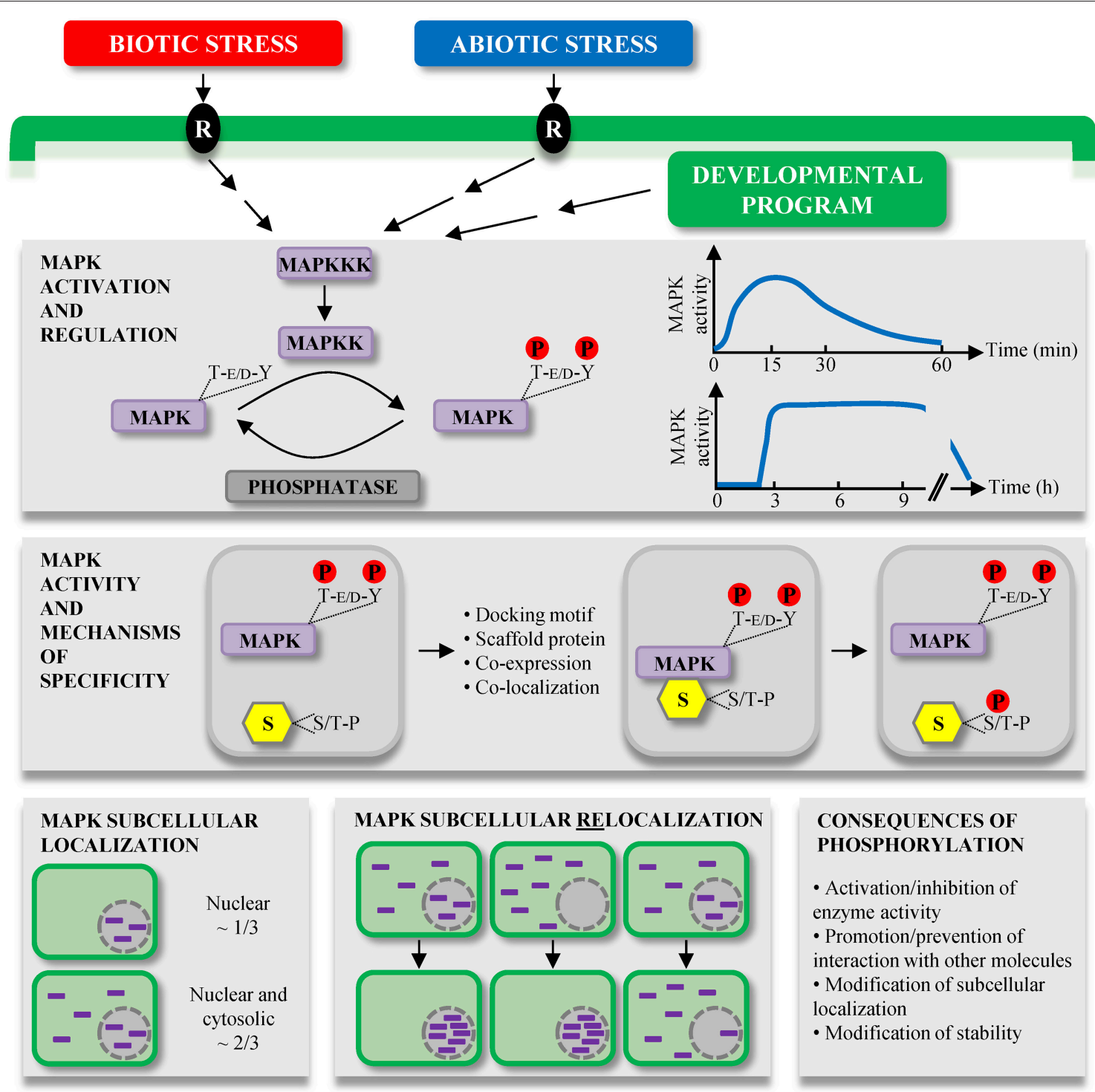

MAPK SUBCELLULAR RELOCALIZATION

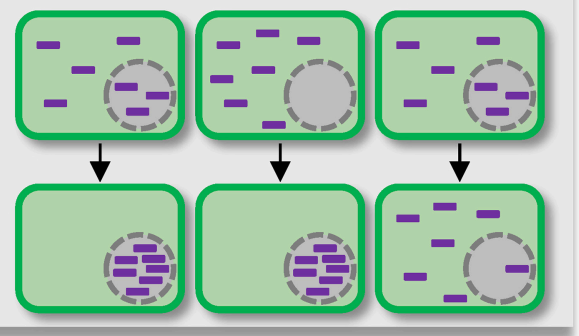

CONSEQUENCES OF PHOSPHORYLATION

- Activation/inhibition of enzyme activity - Promotion/prevention of interaction with other molecules - Modification of subcellular localization - Modification of stability



REGULATION OF IMMUNITY

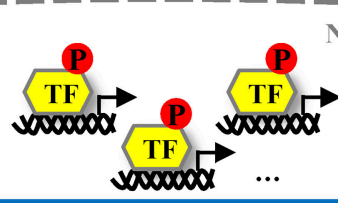

REGULATION OF STRESS TOLERANCE

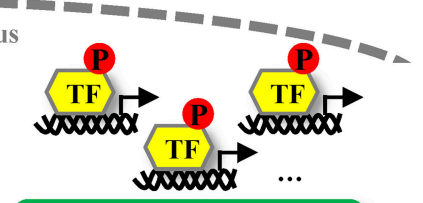

REGULATION OF DEVELOPMENT

FIGURE 1 | Overview of plant MAPK characteristics and signaling. MAPKs constitute the last tier of MAPK modules which are involved in the signaling of multiple environmental stresses, initially perceived by receptors (R), and developmental programs. MAPKs are activated by the dual phosphorylation of their T-E/D-Y motif in their activation loop by MAPKKs. This activation is reversible and MAPK deactivation occurs via their dephosphorylation by protein phosphatases. The kinetics of MAPK activation is variable depending on the stimulus, for instance in a window of several minutes during MTI, or of several hours during ETI. Once activated, MAPKs phosphorylate their substrates (S) on one or several S/T-P motifs, and besides the mandatory presence of these phosphorylation motifs, several mechanisms contribute to the substrate specificity, such as the presence of docking motifs. Substrate phosphorylation by MAPKs may have different consequences, for example their subcellular relocalization. While a few extensively characterized Arabidopsis MAPKs exhibit multiple subcellular localizations, about one third of studied plant MAPKs seem to localize only/predominantly to the nucleus, and two thirds are present in both the cytosol and nucleus. Interestingly, a few cases of MAPK subcellular relocalization were observed upon different stimuli. In almost all instances, the relocalization corresponded to a MAPK nuclear shuttling. The large majority of bona fide MAPK substrates identified so far are transcription factors (TF) (Table 1), phosphorylated either in the cytosol or nucleus. These phosphorylated TF then contribute to the transcriptional reprogramming, allowing the regulation of important processes in which MAPKs are involved. 
TABLE 1 | Selected nuclear substrates of plant MAPKs involved in biotic stress, abiotic stress and development that are discussed in this review.

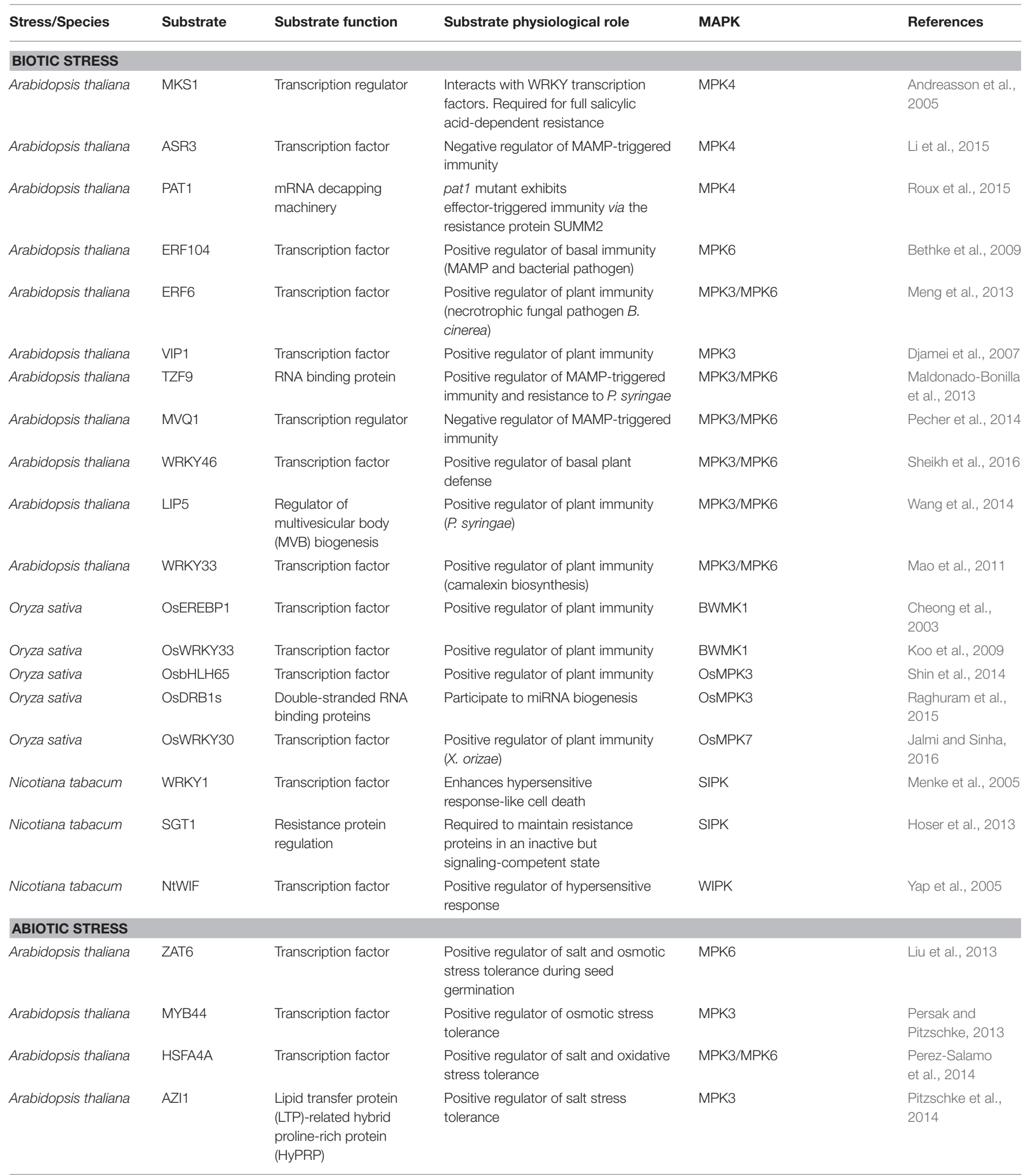


TABLE 1 | Continued

\begin{tabular}{|c|c|c|c|c|c|}
\hline Stress/Species & Substrate & Substrate function & Substrate physiological role & MAPK & References \\
\hline Arabidopsis thaliana & LIP5 & $\begin{array}{l}\text { Regulator of } \\
\text { multivesicular body } \\
\text { (MVB) biogenesis }\end{array}$ & $\begin{array}{l}\text { Positive regulator of heat and salt } \\
\text { stress tolerance }\end{array}$ & MPK3/MPK6 & Wang et al., 2015 \\
\hline Arabidopsis thaliana & HsfA2 & Transcription factor & $\begin{array}{l}\text { Positive regulator of heat stress } \\
\text { tolerance }\end{array}$ & MPK6 & Evrard et al., 2013 \\
\hline Arabidopsis thaliana & ICE1 & Transcription factor & $\begin{array}{l}\text { Positive regulator of cold stress } \\
\text { tolerance }\end{array}$ & MPK3/MPK6 & $\begin{array}{l}\text { Li et al., 2017; } \\
\text { Zhao et al., } 2017\end{array}$ \\
\hline Arabidopsis thaliana & ERF6 & Transcription factor & $\begin{array}{l}\text { Regulates ROS-responsive gene } \\
\text { transcription }\end{array}$ & MPK6 & Wang et al., 2013 \\
\hline Oryza sativa & OsWRKY30 & Transcription factor & Positive regulator of drought tolerance & OsMPK3/OsMPK7/OsMPK14 & Shen et al., 2012 \\
\hline Oryza sativa & SUB1A1 & Transcription factor & $\begin{array}{l}\text { Positive regulator of submergence } \\
\text { stress tolerance }\end{array}$ & OsMPK3 & $\begin{array}{l}\text { Singh and Sinha, } \\
2016\end{array}$ \\
\hline \multicolumn{6}{|l|}{ DEVELOPMENT } \\
\hline Arabidopsis thaliana & AtMAP65-1 & $\begin{array}{l}\text { Microtubule-associated } \\
\text { protein }\end{array}$ & Participates to mitosis & MPK4/MPK6 & $\begin{array}{l}\text { Smertenko et al., } \\
2006\end{array}$ \\
\hline Arabidopsis thaliana & PATL2 & $\begin{array}{l}\text { Binding to } \\
\text { phosphoinositides }\end{array}$ & Participates to cytokinesis & MPK4 & Suzuki et al., 2016 \\
\hline Arabidopsis thaliana & MYB44 & Transcription factor & Functions in seed germination & MPK3/MPK6 & $\begin{array}{l}\text { Nguyen et al., } \\
2012\end{array}$ \\
\hline Arabidopsis thaliana & $\mathrm{SPCH}$ & Transcription factor & Mediates the stomatal lineage & MPK3/MPK6 & $\begin{array}{l}\text { Lampard et al., } \\
2008\end{array}$ \\
\hline Arabidopsis thaliana & BASL & Scaffold protein & $\begin{array}{l}\text { Regulates stomatal asymmetric } \\
\text { division }\end{array}$ & MPK3/MPK6 & Zhang et al., 2015 \\
\hline Arabidopsis thaliana & MYC2 & Transcription factor & $\begin{array}{l}\text { Negative regulator of blue } \\
\text { light-mediated photomorphogenesis }\end{array}$ & MPK6 & Sethi et al., 2014 \\
\hline Arabidopsis thaliana & PIF3 & Transcription factor & $\begin{array}{l}\text { Negative regulator of red } \\
\text { light-mediated photomorphogenesis }\end{array}$ & MPK6 & Xin et al., 2018 \\
\hline Nicotiana tabacum & NtMAP65-1a & $\begin{array}{l}\text { Microtubule-associated } \\
\text { protein }\end{array}$ & $\begin{array}{l}\text { Participates to phragmoplast } \\
\text { expansion }\end{array}$ & NRK1/NTF6 & $\begin{array}{l}\text { Sasabe et al., } \\
2006\end{array}$ \\
\hline
\end{tabular}

required for full salicylic acid (SA)-dependent resistance. MKS1 interacts with the WRKY transcription factors WRKY25 and WRKY33, which both play an important role in plant defense.

MPK4 also phosphorylates the trihelix transcriptional repressor ASR3 (Arabidopsis SH4-related 3) which negatively regulates MTI responses in Arabidopsis (Li et al., 2015). Phosphorylation of ASR3 by MPK4 enhances its DNA binding activity to suppress gene expression and plants overexpressing a phospho-mimetic form of ASR3 are compromised in MTI responses, providing further evidence how MPK4 modifies plant immune gene expression.

Arabidopsis MPK4 regulates the expression of a number of defense genes and in part this may be regulated at the level of mRNA stability. MPK4 associates with and phosphorylates PAT1, a component of the mRNA decapping machinery (Roux et al., 2015). Pat1 mutants are dwarfed and show enhanced immunity that is dependent on the immune receptor SUMM2. Upon MAMP treatment, PAT1 accumulates in cytoplasmic processing (P) bodies which are sites for mRNA decay, linking MPK4 regulated defense gene expression to mRNA stability.

MAMPs, such as the flagellin peptide flg22, rapidly induce ethylene production. Ethylene signaling also results in the activation of MPK6 (Ouaked et al., 2003) and this process seems to be mediated by MKK9 resulting in the MAPK-dependent phosphorylation and activation of the transcription factor EIN3 (ethylene-insensitive 3) (Yoo et al., 2008). Ethylene inactivates the negative regulatory MAPKKK CTR1 (constitutive triple response 1) to activate MKK9 and MAPK activation is governed by the nuclear translocation of MKK9. In this context, Bethke et al. (2009) found the ethylene responsive transcription factor ERF104 as an interactor of MPK6. ERF104 is an important regulator of basal immunity, as erf104 mutants showed enhanced susceptibility to a bacterial pathogen. ERF104 dissociates from MPK6 in a MAMP-dependent manner and MPK6 was found to regulate ERF104 stability in an ethylene-dependent manner.

ERF6 (ethylene response factor 6) is yet another transcription factor of Arabidopsis defense gene expression and is involved in resistance to the necrotrophic fungal pathogen Botrytis cinerea. MPK3/6 can phosphorylate ERF6 and thereby enhance its protein stability. Moreover, phosphomimicking ERF6 constitutively activates defense genes and confers enhanced resistance to $B$. cinerea. However, in contrast to ERF104, the regulation and function of ERF6 is independent of ethylene (Meng et al., 2013).

Apart from the role of ethylene in the regulation of defense gene expression, there is also evidence that MAPKs directly regulate ethylene production via the transcription of $A C S 7, A C S 8$, and ACS11. Here, the WRKY transcription factor WRKY33 
seems to be targeted by MPK3/6 to mediate this transcriptional regulation (Mao et al., 2011; Li et al., 2012).

VIP1 (VIRE2-interacting protein1) is a bZIP transcription factor that associates during Agrobacterium transformation with the bacterial virulence protein VirE2 and helps the T-DNA to be transported into the nucleus. VIP1 is phosphorylated by MPK3 thereby inducing its nuclear relocalization and defense gene expression (Djamei et al., 2007). Phosphorylation of VIP1 also enhances its binding to the VRE (VIP1 response element) and regulates the expression of MPK3 target genes including the transcription factors MYB44 and MYB77 (Pitzschke et al., 2009).

The tandem zinc finger protein 9 (TZF9) is phosphorylated by MPK3/6 and needed for MTI responses (Maldonado-Bonilla et al., 2013). A $t z f 9$ mutant was compromised in specific MTI reactions, including reactive oxygen species (ROS) accumulation, the activation of MAPKs and the expression of several MTI marker genes. $t z f 9$ mutant plants show enhanced susceptibility to virulent $P$. syringae pv. tomato DC3000. TZF9 was localized in cytoplasmic foci that co-localize with markers of P-bodies. TZF9 can bind ribohomopolymers poly(rU) and poly(rG), suggesting a role of post-transcriptional events in plant innate immunity, such as mRNA processing or storage pathways.

The VQ motif (FxxxVQxhTG) of proteins mediates interaction with WRKY transcription factors. Yeast twohybrid interaction screening and in vitro kinase assays coupled to mass spectrometry analysis identified a subset of VQ-motifcontaining Arabidopsis proteins (VQPs) that are phosphorylated by MPK3/6. These proteins were called MPK3/6-targeted VQPs (MVQs) (Pecher et al., 2014). Site-directed mutagenesis of the MVQs and promoter-reporter fusion studies in protoplasts showed that flg22 induced their degradation. The MVQs interact with specific WRKY transcription factors. For MVQ1 a negative role was demonstrated in WRKY-dependent defense gene expression, including that mutation of the VQ-motif abrogates WRKY binding and causes deregulation of defense gene expression.

In a screen for WRKY transcription factors as targets of Arabidopsis MAPKs, WRKY46 was identified as a substrate of MPK3 (Sheikh et al., 2016). In protoplasts, MAMP treatment resulted in destabilization of WRKY46 and the mutation of the phosphorylation sites reduced the MAMP-triggered degradation. WRKY46 overexpression in protoplasts enhanced basal plant defense as shown by the increased expression of the MAMPresponsive gene NHL10. Therefore, MAPK phosphorylation of WRKY46 provides a mechanism to regulate plant defense responses.

Multivesicular bodies (MVBs) play essential roles in many cellular processes, maintaining protein traffic by reversible membrane association of the endosomal sorting complexes required for transports (ESCRTs). Membrane dissociation of ESCRTs is catalyzed by the AAA ATPase SKD1, which is stimulated by LIP5 (LYST interacting protein 5). Arabidopsis LIP5 was found to interact with and becomes phosphorylated by MPK3/6 (Wang et al., 2014). Disruption of LIP5 has little effects on MAMP-, SA-induced defense responses but compromises basal resistance to $P$. syringae which is dependent on its interaction with SKD1. Mutation of MPK phosphorylation sites in LIP5 does not affect interaction with SKD1 but reduces the LIP5 stability and compromises its function. Moreover, pathogen infection increases formation of MVBs in a LIP5-dependent manner, indicating that MPK3/6 regulates the localization of defense molecules by MVBs.

Antimicrobial compounds also play critical roles in plant immunity. In crucifers, phytoalexins and glucosinolate derivatives are important components in defense against pathogens. MPK3/6 are important for the induction of camalexin, the major phytoalexin in Arabidopsis. Phosphorylation of WRKY33 by MPK3/6 was found to be essential for the induction of camalexin synthesis and camalexin biosynthesis genes in Arabidopsis. In wrky33 mutants, the induction and production of camalexin was compromised (Mao et al., 2011). MPK3/6 was also found to affect the accumulation of extracellular thiocyanates which are derived from the IGS indole glucosinolate pathway (Xu et al., 2016). MPK3/6 promoted I3G (indole-3-yl-methylglucosinolate) synthesis and its conversion to 4mi3g (4-methoxyindole-3-yl-methylglucosinolate). By targeting MYB51/122, MPK3/6 control IGS biosynthesis, and via ERF6-mediated expression of CYP81F2 and IGMT1/2, the two MAPKs regulate the conversion of I3G to $4 \mathrm{MI} 3 \mathrm{G}$.

\section{Rice MAPKs}

Plant MAPKs are classified into two subtypes, either having a TEY or TDY motif in their activation loop. In rice, 15 proteins have been classified as MAPKs (Hamel et al., 2006). A rice D-type MAPK with a TDY phosphorylation motif BWMK1 was shown to phosphorylate the transcription factor OsEREBP1, which binds to and enhances the DNA-binding activity of OsEREBP1 to the GCC box (AGCCGCC) which is found in a number of pathogenesis-related $(P R)$ gene promoters. Overexpression of $B M W K 1$ in tobacco plants results in enhanced levels of $\mathrm{SA}$ and $\mathrm{H}_{2} \mathrm{O}_{2}$ and $P R$ genes, including hypersensitive response (HR)-like cell death (Cheong et al., 2003). OsBWMK1 is localized in the nucleus and mediates $P R$ gene expression by activating the OsEREBP1 transcription factor. OsBWMK1 phosphorylates and thereby activates WRKY transcription factors, as shown for OsWRKY33 (Koo et al., 2009). Phosphorylation of WRKY33 enhances its DNA-binding activity to the W-box element (TTGACCA) of several PR gene promoters. Moreover, transient co-expression of OsBWMK1 and OsWRKY33 in Arabidopsis protoplasts enhances SA-dependent expression of a reporter gene that is mediated by a W-box element.

Shin et al. (2014) studied the TEY-type rice MAPK named OsMPK3 and reported phosphorylation of the nuclear basic helix-loop-helix transcription factor OsbHLH65 which specifically binds to E-box promoter cis-elements. OsMPK3 and OsbHLH65 were both induced by treatments with rice blast (Magnaporthe grisea), brown planthopper (Nilaparvata lugens), and the defense-related hormones methyl-JA or SA. These results suggest that OsMPK3 can contribute to defense signaling by phosphorylating the transcription factor OsbHLH65.

MicroRNA (miRNA) biogenesis is a complex process which notably requires double-stranded RNA binding (DRB) proteins. The rice genome encodes for eight DRBs. Raghuram et al. 
studied the $O s D R B$ transcript expression suggesting their involvement in different stress responses (Raghuram et al., 2015). Interestingly, OsMPK3 interacts with and phosphorylates several OsDRB1 isoforms. The authors also obtained similar results in Arabidopsis. Overall the results suggest that MPK3 plays an important role in the regulation of miRNA level (Raghuram et al., 2015).

Group C MAPKs have been poorly characterized. Recently, the group C MAPK OsMPK7 and its upstream MAPKK OsMKK3 were shown to positively regulate resistance against Xanthomonas oryzae infection, known to cause leaf blight disease in rice (Jalmi and Sinha, 2016). In addition, the transcription factor OsWRKY30 interacts with and is phosphorylated by OsMPK7. OsWRKY30 is also involved in the resistance to $X$. oryzae, suggesting that a module composed of OsMKK3OsMPK7-OsWRKY30 contributes to leaf blight disease resistance in rice (Jalmi and Sinha, 2016).

\section{Tobacco MAPKs}

In tobacco, the MPK6 ortholog SIPK (salicylic acid-induced protein kinase) is activated by various biotic and abiotic treatments and overexpression of SIPK triggers cell death. In a targeted yeast two-hybrid approach, the tobacco transcription factor WRKY1 was identified as a potential substrate of SIPK (Menke et al., 2005). WRKY1 is phosphorylated by SIPK, resulting in enhanced DNA-binding activity to a $\mathrm{W}$ box element derived from the tobacco chitinase gene CHN50. Co-expression of SIPK and WRKY1 in Nicotiana benthamiana enhances cell death induction, suggesting that SIPK mediates HR-like cell death via the regulation of WKRY1.

Resistance (R) proteins directly or indirectly sense pathogen effectors inside of host cells and are usually composed of Nucleotide-Binding and Leucine-Rich Repeat domains. SGT1 (Suppressor of G2 allele of SKP1) is required to maintain $\mathrm{R}$ proteins in an inactive but signaling-competent state. Nicotiana tabacum $\mathrm{N}$ protein belongs to the Toll-Interleukin Receptor (TIR)-NB-LRR class of $\mathrm{R}$ proteins and confers resistance to Tobacco Mosaic Virus (TMV). Using mass spectrometry, confocal microscopy and pathogen assays Hoser et al. (2013) showed that SIPK phosphorylates SGT1 and that its phosphorylation state determines its nuclear accumulation and $\mathrm{N}$-mediated resistance to TMV. These data suggest that nucleocytoplasmic partitioning of $\mathrm{N}$ protein is determined by MAPK-dependent SGT1 phosphorylation.

Wounding of plants can be caused by mechanical stress or by herbivore and insect attack and is therefore a stress that bridges abiotic and biotic responses. Hence, WIPK (wound-induced protein kinase) also functions during pathogen responses in tobacco and phosphorylates WIPK interacting factor (NtWIF) (Yap et al., 2005; Chung and Sano, 2007). Overexpression of $N t W I F$ in tobacco plants enhanced while silencing suppressed the HR. NtWIF contains a B3 DNA binding domain, which recognizes the auxin-responsive element (ARE) TGTCTC. NtWIF recognizes ARE motifs and regulates 49 stress-responsive genes, and NtWIF phosphorylation by WIPK enhances its transactivation activity.

\section{ABIOTIC STRESS}

Abiotic stresses pose an important problem in agriculture. The dissection of the signaling pathways mediating abiotic stress tolerance is an essential step to develop more resistant plant species. In various plant species, a number of MAPKs induce responses to numerous abiotic stresses and the targets of these MAPKs are slowly emerging.

\section{Arabidopsis MAPKs \\ Salt, Osmotic Stress and ABA}

$\mathrm{C} 2 \mathrm{H} 2$-type zinc finger proteins (ZFPs) are involved in various plant responses to abiotic stress. ZAT6, an Arabidopsis C2H2type ZFP, regulates root development and nutrient stress responses. However, it also plays a role in the regulation of abiotic stress responses. Salt and osmotic stress induces ZAT6 expression and ZAT6 overexpressing plants show improved seed germination under these stress conditions. ZAT6 interacts and is phosphorylated at two sites by MPK6 in vitro and in planta. Overexpression of a phosphorylation site mutant compromised the enhanced salt and osmotic stress tolerance observed with the wild type ZAT6. These results suggest MPK6 phosphorylation of ZAT6 is required to execute its role during seed germination under salt and osmotic stress conditions (Liu et al., 2013).

The transcription factor MYB44 was identified in a yeast twohybrid screen for interacting partners of MKK4. MAMP-induced expression of MYB44 is regulated by the MPK3-targeted bZIP transcription factor VIP1 (Pitzschke et al., 2009). MPK3 interacts with and phosphorylates MYB44 at Ser145. The mutation of Ser145 in MYB44 to the non-phosphorylatable Ala145 or the phosphomimetic D145 did not change its subcellular localisation, its homo-dimerization nor its DNA-binding activity (Persak and Pitzschke, 2013). However, overexpression of MYB44 resulted in enhanced tolerance to osmotic stress and plants that were slightly more sensitive to ABA. In contrast, and similar to $m p k 3$ plants, overexpression of MYB44 plants with an Ala145 mutation resulted in hypersensitivity to abiotic stress.

In plants, heat shock factors (HSFs) are not only implicated in heat stress but also in a number of abiotic stresses, as shown by estradiol-induced tolerance to salt and oxidative stress of HSFA4A. In contrast, inactivation of HSFA4A results in hypersensitivity to salt stress in Arabidopsis. HSFA4A expression decreases, while an $h s f a 4$ knock out enhances levels of $\mathrm{H}_{2} \mathrm{O}_{2}$ and lipid peroxides. Overexpression of HSFA4A alters expression of a large set of oxidative stress genes. Protein interaction assays show that HSFA4A homodimerization is reduced by replacement of three conserved cysteine residues by alanine residues. MPK3/6 interact with and phosphorylate HSFA4A on three sites, whereby Ser309 seems to be the major residue (Perez-Salamo et al., 2014). Activation of MPK $3 / 6$ led to the transcriptional activation of the HSP17.6A (heat shock 17.6A) gene and an Ala309 variant of HSFA4A strongly reduces the transcriptional induction of HSP17.6A. These data suggest that abiotic stress responses by HSFA4A are mediated by MPK3/6 signaling in Arabidopsis.

Another MPK3 substrate that is involved in salt stress is AZI1. AZI1 is a lipid transfer protein (LTP)-related hybrid 
proline-rich protein (HyPRP) that is phosphorylated by MPK3 in vitro. Co-immunoprecipitation and bimolecular fluorescence complementation assays show that AZI1 interacts with MPK3. AZI1 overexpressing plants are more tolerant whereas azi1 knock out mutants are hypersensitive to salt stress. Furthermore, AZI1 overexpression in the $m p k 3$ genetic background partially suppresses the hypersensitive phenotype of $m p k 3$ plants under salt stress conditions (Pitzschke et al., 2014).

LIP5 is an AAA ATPase in MVB biogenesis and a positive regulator of SKD1 (Suppressor of K+ Transport Growth Defect1). LIP5 is also a substrate of MPK3/6 which plays an important role in the plant immune system (see section above). Wang et al. (2015) showed that the LIP5-regulated MVB pathway is also important in plant responses to abiotic stress. lip5 mutants are compromised in both heat and salt stress tolerance. The function of LIP5 in plant abiotic stress depends on its interaction with SKD1. lip5 mutants accumulate ubiquitinated protein aggregates under heat stress and increased $\mathrm{Na}^{+}$and $\mathrm{Cl}^{-}$ levels under salt stress. LIP5 mediates abiotic stress-induced increases of endocytic vesicles and MVBs. Moreover, LIP5 is involved in the salt-induced increases of intracellular ROS levels. Basal levels of LIP5 phosphorylation by MAPKs and LIP5 stability increase upon salt stress, and mutation of the MAPK-targeted phosphorylation sites in LIP5 reduces its stability and compromises its function. These results suggest that MPK3/6 regulates the MVB pathway via LIP5 phosphorylation and plays a critical role in biotic and abiotic stress responses.

\section{Heat and Cold Stress}

HSFs are key regulators of plant responses to several abiotic stresses, but for heat stress, the transcription factor HsfA2 plays a dominant role. In vitro and in vivo evidence shows that MPK6 specifically targets HsfA2 during heat stress (Evrard et al., 2013). Activation of MPK6 results in enhanced complex formation with $\mathrm{HsfA} 2$ and $\mathrm{HsFA} 2$ phosphorylation induces intracellular relocalization. Interestingly, protein kinase and phosphatase inhibitors revealed that HsfA2 protein stability is also regulated by phosphorylation, but independently of MPK6.

Previous studies showed that the MEKK1-MKK2-MPK4/6 pathway positively regulates responses to cold and freezing in Arabidopsis (Teige et al., 2004). MPK4 and MPK6 are activated by cold stress in plants by MKK2 (Teige et al., 2004). Mutants in $m k k 2$ exhibit increased sensitivity to freezing, whereas constitutive activation of MKK2 enhances freezing tolerance by increasing expression of CBF genes (Teige et al., 2004). CRLK1 interacts with MEKK1, leading to MAPK activation and freezing tolerance (Yang et al., 2010). Recent publications show that, in contrast to the MEKK1-MKK2-MPK4 cascade, which positively regulates cold tolerance, the MKK5-MPK3/MPK6 cascade negatively regulates cold responses by promoting the degradation of ICE1 through phosphorylation. MPK3/6 phosphorylation of ICE1 inhibits its transcriptional activity and facilitates ubiquitination-mediated ICE1 degradation, thereby negatively regulating plant freezing tolerance and $C B F$ expression (Li et al., 2017; Zhao et al., 2017).

\section{ROS}

ROS have been shown to be both important signaling molecules that mediate many developmental and physiological responses, but until now, the transcriptional mechanisms regulating ROSresponsive genes are still little understood. Recently, ROSresponsive cis-acting elements (ROSEs) were identified from the promoters of genes up-regulated by ROS in Arabidopsis. ERF6 (APETALA2/ethylene-responsive element binding factor 6) could bind specifically to the ROSE7/GCC box. Co-expression of ERF6 enhanced luciferase activity driven by ROSE7. The deficient mutants of ERF6 showed growth retardation and higher sensitivity to photo-damage. MPK6 interacts with and phosphorylates ERF6 at both S266 and S269. ERF6 phosphorylation affects ERF6 protein levels resulting in changes in ROS-responsive gene transcription. These data link the regulation of ROS-responsive gene transcription under oxidative stress or fluctuating light conditions to MAPK signaling (Wang et al., 2013).

\section{Rice MAPKs \\ Drought}

Both the WRKY transcription factors and MAPKs have been shown to regulate gene expression in response to biotic and abiotic stresses in Arabidopsis. In rice, Shen et al. (2012) showed that OsWRKY30 interacted with OsMPK3, OsMPK4, OsMPK7, OsMPK14, OsMPK20-4, and OsMPK205, and could be phosphorylated by OsMPK3, OsMPK7, and OsMPK14. Overexpression of OsWRKY30 in rice dramatically increased drought tolerance, but not when the phosphorylation sites were replaced by alanine. This can be explained by the fact that the transcriptional activation of OsWRKY30 was also impaired in the alanine substituted mutant.

\section{Submergence Stress}

Recently, a link between MAPK signaling and the tolerance to submergence stress was uncovered. SUB1A is an ethylene response factor-like protein that regulates a number of responses during submergence of rice. Singh and Sinha (2016) showed that MPK3 is activated by submergence and that MPK3 phosphorylates SUB1A. Furthermore, SUB1A1 binds to the $M P K 3$ promoter and regulates its expression in a positive regulatory loop upon submergence stress. These data suggest a key role for SUB1A and MPK3 in acclimation of rice seedlings to submergence stress.

\section{DEVELOPMENT}

\section{Cell Division}

Cell division depends on microtubule dynamics and organization. The tobacco MAPK module, which includes the MAPK NRK1/NTF6, positively regulates cytokinesis at the level of the phragmoplast, preceeding the synthesis of the cell plates at cell division. NRK1/NTF6 phosphorylates the T579 in the microtubule-associated protein NtMAP65-1a which reduces its microtubule bundling activity (Sasabe et al., 2006). During M phase, NRK1/NTF6 is activated and levels of phosphorylated 
NtMAP65-1 increase concomitant with their accumulation at the phragmoplast. Overexpression of phosphosite mutants of NtMAP65-1a delays progression of M phase and phragmoplast expansion.

Cytokinesis in Arabidopsis is similarly regulated by the formation of the cell plate and a MAPK pathway that is highly homologous to that identified in tobacco and includes the ANP MAPKKKs, the MAPKK MKK6 and the MAPK MPK4. Mutants in these genes are dwarfed and have characteristic cytokinesis defects, such as immature cell plates. MKK6 activates MPK4 in protoplasts and MPK4 kinase activity is high in dividing cells but not in $m k k 6$ mutants. MPK4 protein is localized to the expanding cell plates in dividing cells (Kosetsu et al., 2010). AtMAP65-1 was shown to be phosphorylated during mitosis by CDK and MAPK (Smertenko et al., 2006) and expression of non-phosphorylatable AtMAP65-1 negatively affects mitosis.

Recently, using two-dimensional difference gel electrophoresis to identify phosphorylated proteins from mpk4 mutant plants, Suzuki et al. (2016) could identify the SEC14 domain protein PATELLIN2 (PATL2) as a substrate of MPK4. As MPK4, PATL2 is concentrated at the cell division plane. PATL2 has binding affinity for phosphoinositides which are altered after phosphorylation by MPK4, suggesting a role for the MAPK cascade in the formation of cell plates via a regeneration of membranes during cytokinesis.

\section{Germination}

The phytohormones ABA and gibberellic acid (GA) play antagonistic functions in seed germination and seedling development. In Arabidopsis, the transcriptional regulator MYB44 functions in seed germination (Nguyen et al., 2012). In dry seeds, MYB44 transcript levels are high but decrease during germination. This decrease during germination is inhibited by the GA biosynthesis inhibitor paclobutrazol (PAC) and overexpression of MYB44 results in increased sensitivity of seed germination to ABA or PAC. MYB44 is phosphorylated by MPK3/6 and myb44 mutant phenotype by PAC can be suppressed by wild type MYB44 but not by a MYB44 version that lacks the MAPK-targeted phosphorylation sites. These results indicate that MAPK-dependent phosphorylation of MYB44 is required for its functional role during germination.

\section{Stomatal Development}

Stomata modulate gas exchange between plants and the atmosphere and play critical roles in plant growth and stress adaptation. The stomatal lineage and its subsequent asymmetric divisions in Arabidopsis are mediated by the basic helix-loophelix transcription factor SPEECHLESS (SPCH). The entry into the stomatal lineage is controlled by phosphorylation of $\mathrm{SPCH}$ by either the GSK3-like kinase BIN2 (BRASSINOSTEROID INSENSITIVE 2) and MPK3/6, promoting the degradation of the lineage determinant SPCH (Lampard et al., 2008).

Cell polarization is linked to cell fate determination during asymmetric division of plant stem cells. In Arabidopsis, BASL is polarized to control stomatal asymmetric division. A positive-feedback loop between BASL and the MPK3/6 pathway constitutes a module at the cell cortex. Phosphorylated BASL functions as a scaffold and recruits the MAPKKK YODA and MPK3/6 to the cell cortex (Zhang et al., 2015) and the activation of MPK3/6 reinforces the feedback loop by phosphorylating BASL and inhibiting stomatal fate by phosphorylating SPCH. Therefore, the polarization of the signaling feedback module BASL-MAPK connects cell polarity to cell fate differentiation during asymmetric plant stem cell division.

\section{Photomorphogenesis}

Upon light exposure, plants shift to photomorphogenic growth, during which chlorophyll is synthesized, cotyledons develop and hypocotyl growth slows down. In Arabidopsis, the bHLH transcription factor MYC2 negatively regulates blue lightmediated photomorphogenic growth (Yadav et al., 2005). Blue light activates the MKK3-MPK6 module and this activation is regulated by MYC2 (Sethi et al., 2014). Besides, MPK6 interacts with and phosphorylates MYC2. These results suggest that a feedback regulatory mechanism involving MKK3-MPK6 and MYC2 occurs in response to blue light.

The bHLH transcription factors phytochrome-interacting factors (PIFs) negatively regulate photomorphogenesis. Upon exposure to light, PIFs are phosphorylated and degraded. Recently, Xin et al. reported the involvement of Arabidopsis MKK10-MPK6 module in regulating cotyledon opening upon red light exposure (Xin et al., 2018). Moreover, MPK6 interacts with and phosphorylates PIF3 leading to its degradation. Collectively, the results of Xin et al. suggest that a module composed of MKK10-MPK6-PIF3 regulates seedling photomorphogenesis in response to red light (Xin et al., 2018).

\section{CONCLUSIONS AND FUTURE PROSPECTS}

The majority of currently known (nuclear) MAPK substrates are targets of Arabidopsis MPK3, MPK4, and MPK6, or their probable orthologs in other plant species. This observation is true whatever the context, biotic stress, abiotic stress or development. Identifying the functions of the other MAPKs, notably via the identification of their substrates, thus constitutes an important challenge to better understand signaling networks. Likewise, most of known (nuclear) MAPK substrates were identified in Arabidopsis. It is expected nonetheless that more and more crop MAPK substrates will be identified in the future, thanks notably to the huge progress made these last years in genome sequencing. Translational research, such as targeted approaches on probable crop orthologs of Arabidopsis MAPK substrates, will likely allow developing more resistant/tolerant plant species.

Most currently known bona fide plant MAPK substrates are nuclear and more precisely are transcription factors. This underlines the major role of plant MAPKs as regulators of transcriptional reprogramming, notably allowing within minutes the implementation of adapted responses to environmental constraints. For instance, we showed the strong involvement of Arabidopsis MPK3, MPK4, and MPK6 in the transcriptional reprogramming upon MAMP treatment (Frei Dit Frey et al., 2014). 
Currently, known functions of plant MAPKs are supposed to only rely on their protein kinase activities. However, interestingly, the mechanism of action of mammalian ERK2 (and very probably ERK1) goes beyond its role as a protein kinase. ERK2 was indeed shown to have kinase-independent functions, for instance by promoting activation of proteins by simple direct interaction, by acting as a transcriptional regulator through DNA binding and by disrupting protein complexes (Rodríguez and Crespo, 2011). It would be interesting to investigate if plant MAPKs also have kinase-independent functions.

Besides, plant MAPKs are believed to work as monomers. In contrast, it is known that phosphorylation and scaffold proteins stimulate ERK homodimerization, and that ERK homodimers have cytoplasmic substrates while nuclear substrates are phosphorylated by ERK monomers (Casar et al., 2008). Interestingly, there is also some evidence that different rice MAPKs can directly interact with each other, suggesting that not only MAPK homo- but also MAPK hetero-dimers might play a role in signaling (Sheikh et al., 2013). Therefore, it would be interesting to investigate if such mechanisms also apply to other plant MAPKs and what their functional role is in the respective signaling pathway.

While the dogma is that dual phosphorylation of the T-loop by MAPKK is required for MAPK activation (Anderson et al., 1990; Payne et al., 1991), some other rare mechanisms were also reported. For instance, in the yeast MAPK Hog1/p38 the threonine residue of the TxY motif is essential for the biological activity of the MAPK while the tyrosine residue is not (Bell and Engelberg, 2003). Likewise, the mammalian p38 $\alpha$ MAPK can be activated by direct interaction with the protein TAB1 or through Y323 phosphorylation by $\mathrm{T}$ cell receptor-proximal tyrosine kinases and both ways induce the cis-autophosphorylation of its T-loop (residues Thr180 and Tyr182) (Ge et al., 2002; Salvador et al., 2005). Interestingly, similar mechanisms have been reported for plant MAPKs. Indeed, Arabidopsis MPK8 can be activated through direct interaction with calmodulins in a $\mathrm{Ca}^{2+}$-dependent manner and moreover the activation does not require MPK8 autophosphorylation (Takahashi et al., 2011). Also in rice, the calcium-dependent protein kinase CPK18 is able to activate MPK5 (AtMPK3 ortholog) by phosphorylation, however this phosphorylation mainly occurs on two conserved threonine residues in the N-terminal region (Thr14 and Thr32) of MPK5, but not on its TxY motif (Xie et al., 2014). The observation of these unconventional MAPK activation mechanisms strongly suggests that others may exist as well.

\section{REFERENCES}

Ahlfors, R., Macioszek, V., Rudd, J., Brosché, M., Schlichting, R., Scheel, D., et al. (2004). Stress hormone-independent activation and nuclear translocation of mitogen-activated protein kinases in Arabidopsis thaliana during ozone exposure. Plant J. 40, 512-522. doi: 10.1111/j.1365-313X.2004. 02229.x

Anderson, N. G., Maller, J. L., Tonks, N. K., and Sturgill, T. W. (1990). Requirement for integration of signals from two distinct phosphorylation pathways for activation of MAP kinase. Nature 343, 651-653. doi: 10.1038/343651a0
The current model of MAPK signaling is represented by the MAPK module where a MAPKKK activates one/several MAPKK(s) which in turn activate(s) one/several MAPK(s) that finally phosphorylate(s) its/their substrates. However, data suggest that MAPKKKs could also have other substrates than MAPKKs, thus forming signaling shortcuts. Indeed, Arabidopsis MEKK1 can directly interact with the transcription factor WRKY53 and bind the WRKY53 promoter (Miao et al., 2007). The authors also reported the in vitro phosphorylation of WRKY53 by MEKK1, but no in planta evidence has supported this result yet. Likewise, Arabidopsis MAP3K16 interacts with and phosphorylates in vitro the negative regulator of ABA response ABR1, but here as well in planta evidence is lacking (Choi et al., 2017). Arabidopsis MAP3K20 directly interacts with MPK18 and phosphorylates MPK18 in vitro on the TDY motif of its activation loop (Benhamman et al., 2017). This signaling shortcut is suggested to occur in parallel to a classical MAPK module, constituted of MAP3K20, $\mathrm{MKK} 3$, and an unknown MAPK, in cortical microtubule function.

Besides individual PTM events, such as phosphorylation, PTM crosstalk constitutes an additional level in the regulation of protein properties (Hunter, 2007). Protein phosphorylation is likely the most abundant PTM found in eukaryotes but other PTMs are also frequent, such as acetylation, methylation, ubiquitination and SUMOylation (Minguez et al., 2012). While numerous studies were made to uncover plant phosphoproteomes, other PTMs have been poorly explored. Substantial efforts will be required to identify the whole set of protein PTMs, thereby allowing the study of PTM crosstalk and the uncovering of new regulatory mechanisms.

\section{AUTHOR CONTRIBUTIONS}

All authors listed have made a substantial, direct and intellectual contribution to the work, and approved it for publication.

\section{ACKNOWLEDGMENTS}

This work was supported by the King Abdullah University of Science and Technology (BAS/1/1062-01-0, URF/1/2574-01-01, and URF/1/2965-01-01). The IPS2 benefits from the support of the LabEx Saclay Plant Sciences-SPS (ANR-10-LABX-0040SPS). We also would like to thank the reviewers for their useful suggestions. responses. EMBO J. 24, 2579-2589. doi: 10.1038/sj.emboj.7600737

Bardwell, L. (2006). Mechanisms of MAPK signalling specificity. Biochem. Soc. Trans. 34, 837-841. doi: 10.1042/BST0340837

Bardwell, L., and Thorner, J. (1996). A conserved motif at the amino termini of MEKs might mediate high-affinity interaction with the cognate MAPKs. Trends Biochem. Sci. 21, 373-374. doi: 10.1016/S0968-0004(96)30032-7 
Bartels, S., González Besteiro, M. A., Lang, D., and Ulm, R. (2010). Emerging functions for plant MAP kinase phosphatases. Trends Plant Sci. 15, 322-329. doi: 10.1016/j.tplants.2010.04.003

Beck, M., Komis, G., Ziemann, A., Menzel, D., and Samaj, J. (2011). Mitogenactivated protein kinase 4 is involved in the regulation of mitotic and cytokinetic microtubule transitions in Arabidopsis thaliana. New Phytol. 189, 1069-1083. doi: 10.1111/j.1469-8137.2010.03565.x

Bell, M., and Engelberg, D. (2003). Phosphorylation of Tyr-176 of the yeast MAPK Hog1/p38 is not vital for Hog1 biological activity. J. Biol. Chem. 278, 14603-14606. doi: 10.1074/jbc.C300006200

Benhamman, R., Bai, F., Drory, S. B., Loubert-Hudon, A., Ellis, B., and Matton, D. P. (2017). The Arabidopsis mitogen-activated protein kinase kinase kinase 20 (MKKK20) acts upstream of MKK3 and MPK18 in two separate signaling pathways involved in root microtubule functions. Front. Plant Sci. 8:1352. doi: 10.3389/fpls.2017.01352

Berriri, S., Garcia, A. V., Dit Frey, N. F., Rozhon, W., Pateyron, S., Leonhardt, N., et al. (2012). Constitutively active mitogen-activated protein kinase versions reveal functions of Arabidopsis MPK4 in pathogen defense signaling. Plant Cell 24, 4281-4293. doi: 10.1105/tpc.112.101253

Bethke, G., Pecher, P., Eschen-Lippold, L., Tsuda, K., Katagiri, F., Glazebrook, J., et al. (2012). Activation of the Arabidopsis thaliana mitogen-activated protein kinase MPK11 by the flagellin-derived elicitor peptide, flg22. Mol. Plant Microbe Interact. 25, 471-480. doi: 10.1094/MPMI-11-11-0281

Bethke, G., Unthan, T., Uhrig, J. F., Pöschl, Y., Gust, A. A., Scheel, D., et al. (2009). Flg22 regulates the release of an ethylene response factor substrate from MAP kinase 6 in Arabidopsis thaliana via ethylene signaling. Proc. Natl. Acad. Sci. U.S.A. 106, 8067-8072. doi: 10.1073/pnas.0810206106

Bigeard, J., Rayapuram, N., Pflieger, D., and Hirt, H. (2014). Phosphorylationdependent regulation of plant chromatin and chromatin-associated proteins. Proteomics 14, 2127-2140. doi: 10.1002/pmic.201400073

Biondi, R. M., and Nebreda, A. R. (2003). Signalling specificity of Ser/Thr protein kinases through docking-site-mediated interactions. Biochem. J. 372, 1-13. doi: 10.1042/bj20021641

Brock, A. K., Willmann, R., Kolb, D., Grefen, L., Lajunen, H. M., Bethke, G., et al. (2010). The Arabidopsis mitogen-activated protein kinase phosphatase PP2C5 affects seed germination, stomatal aperture, and abscisic acid-inducible gene expression. Plant Physiol. 153, 1098-1111. doi: 10.1104/pp.110.156109

Canagarajah, B. J., Khokhlatchev, A., Cobb, M. H., and Goldsmith, E. J. (1997). Activation mechanism of the MAP kinase ERK2 by dual phosphorylation. Cell 90, 859-869. doi: 10.1016/S0092-8674(00)80351-7

Carrasco, J. L., Castelló, M. J., Naumann, K., Lassowskat, I., Navarrete-Gómez, M., Scheel, D., et al. (2014). Arabidopsis protein phosphatase DBP1 nucleates a protein network with a role in regulating plant defense. PLoS ONE 9:e90734. doi: 10.1371/journal.pone.0090734

Casar, B., Pinto, A., and Crespo, P. (2008). Essential role of ERK dimers in the activation of cytoplasmic but not nuclear substrates by ERK-scaffold complexes. Mol. Cell 31, 708-721. doi: 10.1016/j.molcel.2008.07.024

Cheng, Z., Li, J. F., Niu, Y., Zhang, X. C., Woody, O. Z., Xiong, Y., et al. (2015). Pathogen-secreted proteases activate a novel plant immune pathway. Nature 521, 213-216. doi: 10.1038/nature 14243

Chen, T., Zhou, B., Duan, L., Zhu, H., and Zhang, Z. (2017). MtMAPKK4 is an essential gene for growth and reproduction of Medicago truncatula. Physiol. Plant. 159, 492-503. doi: 10.1111/ppl.12533

Cheong, Y. H., Moon, B. C., Kim, J. K., Kim, C. Y., Kim, M. C., Kim, I. H., et al. (2003). BWMK1, a rice mitogen-activated protein kinase, locates in the nucleus and mediates pathogenesis-related gene expression by activation of a transcription factor. Plant Physiol. 132, 1961-1972. doi: 10.1104/pp.103. 023176

Choi, S.-W., Lee, S.-B., Na, Y.-J., Jeung, S.-G., and Kim, S. Y. (2017). Arabidopsis MAP3K16 and other salt-inducible MAP3Ks regulate ABA response redundantly. Mol. Cells 40, 230-242. doi: 10.14348/molcells.2017.0002

Chung, K.-M., and Sano, H. (2007). Transactivation of wound-responsive genes containing the core sequence of the auxin-responsive element by a woundinduced protein kinase-activated transcription factor in tobacco plants. Plant Mol. Biol. 65, 763-773. doi: 10.1007/s11103-007-9240-1

Cohen, P. (2000). The regulation of protein function by multisite phosphorylation-a 25 year update. Trends Biochem. Sci. 25, 596-601. doi: 10.1016/S0968-0004(00)01712-6
Colcombet, J., and Hirt, H. (2008). Arabidopsis MAPKs: a complex signalling network involved in multiple biological processes. Biochem. J. 413, 217-226. doi: 10.1042/BJ20080625

Coronado, M. J., González-Melendi, P., Segu,í, J. M., Ramírez, C., Bárány, I., Testillano, P. S., et al. (2002). MAPKs entry into the nucleus at specific interchromatin domains in plant differentiation and proliferation processes. $J$. Struct. Biol. 140, 200-213. doi: 10.1016/S1047-8477(02)00542-7

Dahan, J., Wendehenne, D., Ranjeva, R., Pugin, A., and Bourque, S. (2010). Nuclear protein kinases: still enigmatic components in plant cell signalling. New Phytol. 185, 355-368. doi: 10.1111/j.1469-8137.2009.03085.x

Danquah, A., de Zélicourt, A., Boudsocq, M., Neubauer, J., Frei Dit Frey, N., Leonhardt, N., et al. (2015). Identification and characterization of an ABAactivated MAP kinase cascade in Arabidopsis thaliana. Plant J. 82, 232-244. doi: $10.1111 /$ tpj.12808

Dardick, C., Chen, J., Richter, T., Ouyang, S., and Ronald, P. (2007). The rice kinase database. A phylogenomic database for the rice kinome. Plant Physiol. 143, 579-586. doi: 10.1104/pp.106.087270

Denoux, C., Galletti, R., Mammarella, N., Gopalan, S., Werck, D., De Lorenzo, G., et al. (2008). Activation of defense response pathways by OGs and Flg22 elicitors in Arabidopsis seedlings. Mol. Plant 1, 423-445. doi: $10.1093 / \mathrm{mp} / \mathrm{ssn} 019$

Djamei, A., Pitzschke, A., Nakagami, H., Rajh, I., and Hirt, H. (2007). Trojan horse strategy in Agrobacterium transformation: abusing MAPK defense signaling. Science 318, 453-456. doi: 10.1126/science.1148110

Dóczi, R., Okrész, L., Romero, A. E., Paccanaro, A., and Bogre, L. (2012). Exploring the evolutionary path of plant MAPK networks. Trends Plant Sci. 17, 518-525. doi: 10.1016/j.tplants.2012.05.009

Durek, P., Schmidt, R., Heazlewood, J. L., Jones, A., MacLean, D., Nagel, A., et al. (2010). PhosPhAt: the Arabidopsis thaliana phosphorylation site database. An update. Nucleic Acids Res. 38, D828-D834. doi: 10.1093/nar/gkp810

Evrard, A., Kumar, M., Lecourieux, D., Lucks, J., von Koskull-Döring, P., and Hirt, H. (2013). Regulation of the heat stress response in Arabidopsis by MPK6-targeted phosphorylation of the heat stress factor HsfA2. PeerJ 1:e59. doi: $10.7717 /$ peerj. 59

Feilner, T., Hultschig, C., Lee, J., Meyer, S., Immink, R. G., Koenig, A., et al. (2005). High throughput identification of potential Arabidopsis mitogenactivated protein kinases substrates. Mol. Cell. Proteomics 4, 1558-1568. doi: 10.1074/mcp.M500007-MCP200

Frei Dit Frey, N., Garcia, A. V., Bigeard, J., Zaag, R., Bueso, E., Garmier, M., et al. (2014). Functional analysis of Arabidopsis immune-related MAPKs uncovers a role for MPK3 as negative regulator of inducible defenses. Genome Biol. 15:R87. doi: 10.1186/gb-2014-15-6-r87

Fried, H., and Kutay, U. (2003). Nucleocytoplasmic transport: taking an inventory. Cell. Mol. Life Sci. 60, 1659-1688. doi: 10.1007/s00018-003-3070-3

Galletti, R., Ferrari, S., and De Lorenzo, G. (2011). Arabidopsis MPK3 and MPK6 play different roles in basal and oligogalacturonide- or flagellininduced resistance against Botrytis cinerea. Plant Physiol. 157, 804-814. doi: 10.1104/pp.111.174003

Gao, M., Liu, J., Bi, D., Zhang, Z., Cheng, F., Chen, S., et al. (2008). MEKK1, MKK1/MKK2 and MPK4 function together in a mitogen-activated protein kinase cascade to regulate innate immunity in plants. Cell Res. 18, 1190-1198. doi: 10.1038/cr.2008.300

Ge, B., Gram, H., Di Padova, F., Huang, B., New, L., Ulevitch, R. J., et al. (2002). MAPKK-independent activation of p38alpha mediated by TAB1-dependent autophosphorylation of p38alpha. Science 295, 1291-1294. doi: 10.1126/science.1067289

Gómez-Gómez, L., and Boller, T. (2000). FLS2: an LRR receptor-like kinase involved in the perception of the bacterial elicitor flagellin in Arabidopsis. Mol. Cell 5, 1003-1011. doi: 10.1016/S1097-2765(00)80265-8

González Besteiro, M. A., and Ulm, R. (2013). Phosphorylation and stabilization of Arabidopsis MAP kinase phosphatase 1 in response to UV-B stress. J. Biol. Chem. 288, 480-486. doi: 10.1074/jbc.M112.434654

Good, M. C., Zalatan, J. G., and Lim, W. A. (2011). Scaffold proteins: hubs for controlling the flow of cellular information. Science 332, 680-686. doi: 10.1126/science.1198701

Good, M., Tang, G., Singleton, J., Reményi, A., and Lim, W. A. (2009). The Ste5 scaffold directs mating signaling by catalytically unlocking the Fus3 MAP kinase for activation. Cell 136, 1085-1097. doi: 10.1016/j.cell.2009.01.049 
Hamel, L.-P., Nicole, M.-C., Sritubtim, S., Morency, M.-J., Ellis, M., Ehlting, J., et al. (2006). Ancient signals: comparative genomics of plant MAPK and MAPKK gene families. Trends Plant Sci. 11, 192-198. doi: 10.1016/j.tplants.2006.02.007

Hettenhausen, C., Baldwin, I. T., and Wu, J. (2012). Silencing MPK4 in Nicotiana attenuata enhances photosynthesis and seed production but compromises abscisic acid-induced stomatal closure and guard cell-mediated resistance to Pseudomonas syringae pv tomato DC3000. Plant Physiol. 158, 759-776. doi: 10.1104/pp.111.190074

Hoehenwarter, W., Thomas, M., Nukarinen, E., Egelhofer, V., Röhrig, H., Weckwerth, W., et al. (2013). Identification of novel in vivo MAP kinase substrates in Arabidopsis thaliana through use of tandem metal oxide affinity chromatography. Mol. Cell. Proteomics 12, 369-380. doi: 10.1074/mcp.M112.020560

Holmberg, C. I., Tran, S. E., Eriksson, J. E., and Sistonen, L. (2002). Multisite phosphorylation provides sophisticated regulation of transcription factors. Trends Biochem. Sci. 27, 619-627. doi: 10.1016/S0968-0004(02)02207-7

Hoser, R., Zurczak, M., Lichocka, M., Zuzga, S., Dadlez, M., Samuel, M. A., et al. (2013). Nucleocytoplasmic partitioning of tobacco $\mathrm{N}$ receptor is modulated by SGT1. New Phytol. 200, 158-171. doi: 10.1111/nph.12347

Hunter, T. (2007). The age of crosstalk: phosphorylation, ubiquitination, and beyond. Mol. Cell 28, 730-738. doi: 10.1016/j.molcel.2007.11.019

Ichimura, K., Mizoguchi, T., Irie, K., Morris, P., Giraudat, J., Matsumoto, K., et al. (1998). Isolation of ATMEKK1 (a MAP kinase kinase kinase)-interacting proteins and analysis of a MAP kinase cascade in Arabidopsis. Biochem. Biophys. Res. Commun. 253, 532-543. doi: 10.1006/bbrc.1998.9796

Im, J. H., Lee, H., Kim, J., Kim, H. B., and An, C. S. (2012). Soybean MAPK, GMK1 is dually regulated by phosphatidic acid and hydrogen peroxide and translocated to nucleus during salt stress. Mol. Cells 34, 271-278. doi: 10.1007/s10059-012-0092-4

Ishihama, N., Yamada, R., Yoshioka, M., Katou, S., and Yoshioka, H. (2011). Phosphorylation of the Nicotiana benthamiana WRKY8 transcription factor by MAPK functions in the defense response. Plant Cell 23, 1153-1170. doi: 10.1105/tpc.110.081794

Jacobs, D., Glossip, D., Xing, H., Muslin, A. J., and Kornfeld, K. (1999). Multiple docking sites on substrate proteins form a modular system that mediates recognition by ERK MAP kinase. Genes Dev. 13, 163-175. doi: 10.1101/gad.13.2.163

Jalmi, S. K., and Sinha, A. K. (2016). Functional involvement of a mitogen activated protein kinase module, OsMKK3-OsMPK7-OsWRK30 in mediating resistance against Xanthomonas oryzae in rice. Sci. Rep. 6:37974. doi: 10.1038/srep37974

Jammes, F., Song, C., Shin, D., Munemasa, S., Takeda, K., Gu, D., et al. (2009). MAP kinases MPK9 and MPK12 are preferentially expressed in guard cells and positively regulate ROS-mediated ABA signaling. Proc. Natl. Acad. Sci. U.S.A. 106, 20520-20525. doi: 10.1073/pnas.0907205106

Kholodenko, B. N. (2006). Cell-signalling dynamics in time and space. Nat. Rev. Mol. Cell Biol. 7, 165-176. doi: 10.1038/nrm1838

Khoury, G. A., Baliban, R. C., and Floudas, C. A. (2011). Proteome-wide posttranslational modification statistics: frequency analysis and curation of the swiss-prot database. Sci. Rep. 1:90. doi: 10.1038/srep00090

Koo, S. C., Moon, B. C., Kim, J. K., Kim, C. Y., Sung, S. J., Kim, M. C., et al. (2009). OsBWMK1 mediates SA-dependent defense responses by activating the transcription factor OsWRKY33. Biochem. Biophys. Res. Commun. 387, 365-370. doi: 10.1016/j.bbrc.2009.07.026

Koo, S. C., Yoon, H. W., Kim, C. Y., Moon, B. C., Cheong, Y. H., Han, H. J., et al. (2007). Alternative splicing of the OsBWMK1 gene generates three transcript variants showing differential subcellular localizations. Biochem. Biophys. Res. Commun. 360, 188-193. doi: 10.1016/j.bbrc.2007.06.052

Kosetsu, K., Matsunaga, S., Nakagami, H., Colcombet, J., Sasabe, M., Soyano, T., et al. (2010). The MAP kinase MPK4 is required for cytokinesis in Arabidopsis thaliana. Plant Cell 22, 3778-3790. doi: 10.1105/tpc.110.077164

Kumar, K. R. R., and Kirti, P. B. (2010). A mitogen-activated protein kinase, AhMPK6 from peanut localizes to the nucleus and also induces defense responses upon transient expression in tobacco. Plant Physiol. Biochem. 48, 481-486. doi: 10.1016/j.plaphy.2010.03.010

Kumar, K. R. R., Srinivasan, T., and Kirti, P. B. (2009). A mitogen-activated protein kinase gene, AhMPK3 of peanut: molecular cloning, genomic organization, and heterologous expression conferring resistance against Spodoptera litura in tobacco. Mol. Genet. Genomics 282, 65-81. doi: 10.1007/s00438-009-0446-6
Lampard, G. R., Macalister, C. A., and Bergmann, D. C. (2008). Arabidopsis stomatal initiation is controlled by MAPK-mediated regulation of the bHLH SPEECHLESS. Science 322, 1113-1116. doi: 10.1126/science.1162263

Lander, E. S., Linton, L. M., Birren, B., Nusbaum, C., Zody, M. C., Baldwin, J., et al. (2001). Initial sequencing and analysis of the human genome. Nature 409, 860-921. doi: 10.1038/35057062

Lee, J., Rudd, J. J., Macioszek, V. K., and Scheel, D. (2004). Dynamic changes in the localization of MAPK cascade components controlling pathogenesis-related (PR) gene expression during innate immunity in parsley. J. Biol. Chem. 279, 22440-22448. doi: 10.1074/jbc.M401099200

Lee, J. S., and Ellis, B. E. (2007). Arabidopsis MAPK phosphatase 2 (MKP2) positively regulates oxidative stress tolerance and inactivates the MPK3 and MPK6 MAPKs. J. Biol. Chem. 282, 25020-25029. doi: 10.1074/jbc.M701888200

Lehti-Shiu, M. D., and Shiu, S. H. (2012). Diversity, classification and function of the plant protein kinase superfamily. Philos. Trans. R. Soc. Lond. B Biol. Sci. 367, 2619-2639. doi: 10.1098/rstb.2012.0003

Liang, W., Yang, B., Yu, B.-J., Zhou, Z., Li, C., Jia, M., et al. (2013). Identification and analysis of MKK and MPK gene families in canola (Brassica napus L.). BMC Genomics 14:392. doi: 10.1186/1471-2164-14-392

Li, B., Jiang, S., Yu, X., Cheng, C., Chen, S., Cheng, Y., et al. (2015). Phosphorylation of trihelix transcriptional repressor ASR3 by MAP KINASE4 negatively regulates Arabidopsis immunity. Plant Cell 27, 839-856. doi: $10.1105 /$ tpc. 114.134809

Li, G., Meng, X., Wang, R., Mao, G., Han, L., Liu, Y., et al. (2012). Duallevel regulation of ACC synthase activity by MPK3/MPK6 cascade and its downstream WRKY transcription factor during ethylene induction in Arabidopsis. PLoS Genet. 8:e1002767. doi: 10.1371/journal.pgen.1002767

Ligterink, W., Kroj, T., zur Nieden, U., Hirt, H., and Scheel, D. (1997). Receptormediated activation of a MAP kinase in pathogen defense of plants. Science 276, 2054-2057. doi: 10.1126/science.276.5321.2054

Li, H., Ding, Y., Shi, Y., Zhang, X., Zhang, S., Gong, Z., et al. (2017). MPK3- and MPK6-Mediated ICE1 Phosphorylation Negatively Regulates ICE1 Stability and Freezing Tolerance in Arabidopsis. Dev. Cell 43, 630-642.e4. doi: 10.1016/j.devcel.2017.09.025

Liu, J. Z., Horstman, H. D., Braun, E., Graham, M. A., Zhang, C., Navarre, D., et al. (2011). Soybean homologs of MPK4 negatively regulate defense responses and positively regulate growth and development. Plant Physiol. 157, 1363-1378. doi: $10.1104 / p p .111 .185686$

Liu, X. M., Nguyen, X. C., Kim, K. E., Han, H. J., Yoo, J., Lee, K., et al. (2013). Phosphorylation of the zinc finger transcriptional regulator ZAT6 by MPK6 regulates Arabidopsis seed germination under salt and osmotic stress. Biochem. Biophys. Res. Commun. 430, 1054-1059. doi: 10.1016/j.bbrc.2012.12.039

Li, Y., Zhang, L., Wang, X., Zhang, W., Hao, L., Chu, X., et al. (2013). Cotton GhMPK6a negatively regulates osmotic tolerance and bacterial infection in transgenic Nicotiana benthamiana, and plays a pivotal role in development. FEBS J.. 280, 5128-5144. doi: 10.1111/febs.12488

Lothrop, A. P., Torres, M. P., and Fuchs, S. M. (2013). Deciphering post-translational modification codes. FEBS Lett. 587, 1247-1257. doi: 10.1016/j.febslet.2013.01.047

Lumbreras, V., Vilela, B., Irar, S., Solé, M., Capellades, M., Valls, M., et al. (2010). MAPK phosphatase MKP2 mediates disease responses in Arabidopsis and functionally interacts with MPK3 and MPK6. Plant J. 63, 1017-1030. doi: 10.1111/j.1365-313X.2010.04297.x

Maldonado-Bonilla, L. D., Eschen-Lippold, L., Gago-Zachert, S., Tabassum, N., Bauer, N., Scheel, D., et al. (2013). The Arabidopsis tandem zinc finger 9 protein binds RNA and mediates pathogen-associated molecular patterntriggered immune responses. Plant Cell Physiol. 55, 412-425. doi: 10.1093/pcp/ pct175

Mao, G., Meng, X., Liu, Y., Zheng, Z., Chen, Z., and Zhang, S. (2011). Phosphorylation of a WRKY transcription factor by two pathogen-responsive MAPKs drives phytoalexin biosynthesis in Arabidopsis. Plant Cell 23, 1639-1653. doi: 10.1105/tpc.111.084996

MAPK-Group. (2002). Mitogen-activated protein kinase cascades in plants: a new nomenclature. Trends Plant Sci. 7, 301-308. doi: 10.1016/S1360-1385(02)02302-6

Marchi, M., D’Antoni, A., Formentini, I., Parra, R., Brambilla, R., Ratto, G. M., et al. (2008). The N-terminal domain of ERK1 accounts for the functional differences with ERK2. PLoS ONE 3:e3873. doi: 10.1371/journal.pone.0003873 
McDonald, P. H., Chow, C. W., Miller, W. E., Laporte, S. A., Field, M. E., Lin, F. T., et al. (2000). Beta-arrestin 2: a receptor-regulated MAPK scaffold for the activation of JNK3. Science 290, 1574-1577. doi: 10.1126/science.290.5496.1574

Meier, I. (2007). Composition of the plant nuclear envelope: theme and variations. J. Exp. Bot. 58, 27-34. doi: 10.1093/jxb/erl009

Menges, M., Dóczi, R., Okrész, L., Morandini, P., Mizzi, L., Soloviev, M., et al. (2008). Comprehensive gene expression atlas for the Arabidopsis MAP kinase signalling pathways. New Phytol. 179, 643-662. doi: 10.1111/j.1469-8137.2008.02552.X

Meng, X., Xu, J., He, Y., Yang, K. Y., Mordorski, B., Liu, Y., et al. (2013). Phosphorylation of an ERF transcription factor by Arabidopsis MPK3/MPK6 regulates plant defense gene induction and fungal resistance. Plant Cell 25, 1126-1142. doi: 10.1105/tpc.112.109074

Menke, F. L., Kang, H.-G., Chen, Z., Park, J. M., Kumar, D., and Klessig, D. F. (2005). Tobacco transcription factor WRKY1 is phosphorylated by the MAP kinase SIPK and mediates HR-like cell death in tobacco. Mol. Plant Microbe Interact. 18, 1027-1034. doi: 10.1094/MPMI-18-1027

Miao, Y., Laun, T. M., Smykowski, A., and Zentgraf, U. (2007). Arabidopsis MEKK1 can take a short cut: it can directly interact with senescence-related WRKY53 transcription factor on the protein level and can bind to its promoter. Plant Mol. Biol. 65, 63-76. doi: 10.1007/s11103-007-9198-Z

Minguez, P., Parca, L., Diella, F., Mende, D. R., Kumar, R., Helmer-Citterich, M., et al. (2012). Deciphering a global network of functionally associated posttranslational modifications. Mol. Syst. Biol. 8:599. doi: 10.1038/msb.2012.31

Müller, J., Beck, M., Mettbach, U., Komis, G., Hause, G., Menzel, D., et al. (2010). Arabidopsis MPK6 is involved in cell division plane control during early root development, and localizes to the pre-prophase band, phragmoplast, trans-Golgi network and plasma membrane. Plant J. 61, 234-248. doi: 10.1111/j.1365-313X.2009.04046.x

Munnik, L., Meskiene, C., Beyerly, M., Calderini, O., Beyerly, J., Musgrave, A., et al. (1999). Distinct osmo-sensing protein kinase pathways are involved in signalling moderate and severe hyper-osmotic stress. Plant J. 20, 381-388. doi: 10.1046/j.1365-313x.1999.00610.x

Nguyen, X. C., Hoang, M. H., Kim, H. S., Lee, K., Liu, X. M., Kim, S. H., et al. (2012). Phosphorylation of the transcriptional regulator MYB44 by mitogen activated protein kinase regulates Arabidopsis seed germination. Biochem. Biophys. Res. Commun. 423, 703-708. doi: 10.1016/j.bbrc.2012.06.019

Nühse, T. S., Peck, S. C., Hirt, H., and Boller, T. (2000). Microbial elicitors induce activation and dual phosphorylation of the Arabidopsis thaliana MAPK 6. J. Biol. Chem. 275, 7521-7526. doi: 10.1074/jbc.275.11.7521

Oh, C. S., and Martin, G. B. (2011). Tomato 14-3-3 protein TFT7 interacts with a MAP kinase kinase to regulate immunity-associated programmed cell death mediated by diverse disease resistance proteins. J. Biol. Chem. 286, 14129-14136. doi: 10.1074/jbc.M111.225086

Olsen, J. V., and Mann, M. (2013). Status of large-scale analysis of posttranslational modifications by mass spectrometry. Mol. Cell. Proteomics 12, 3444-3452. doi: 10.1074/mcp.O113.034181

Ortiz-Masia, D., Perez-Amador, M. A., Carbonell, J., and Marcote, M. J. (2007). Diverse stress signals activate the $\mathrm{C} 1$ subgroup MAP kinases of Arabidopsis. FEBS Lett. 581, 1834-1840. doi: 10.1016/j.febslet.2007.03.075

Ouaked, F., Rozhon, W., Lecourieux, D., and Hirt, H. (2003). A MAPK pathway mediates ethylene signaling in plants. EMBO J. 22, 1282-1288. doi: 10.1093/emboj/cdg131

Ovecka, M., Takác, T., Komis, G., Vadovic, P., Bekešová, S., Doskocilová, A., et al. (2014). Salt-induced subcellular kinase relocation and seedling susceptibility caused by overexpression of Medicago SIMKK in Arabidopsis. J. Exp. Bot. 65, 2335-2350. doi: 10.1093/jxb/eru115

Pan, J., Zhang, M., Kong, X., Xing, X., Liu, Y., Zhou, Y., et al. (2012). ZmMPK17, a novel maize group D MAP kinase gene, is involved in multiple stress responses. Planta 235, 661-676. doi: 10.1007/s00425-011-1510-0

Park, H. C., Song, E. H., Nguyen, X. C., Lee, K., Kim, K. E., Kim, H. S., et al. (2011). Arabidopsis MAP kinase phosphatase 1 is phosphorylated and activated by its substrate AtMPK6. Plant Cell Rep. 30, 1523-1531. doi: 10.1007/s00299-011-1064-4

Payne, D. M., Rossomando, A. J., Martino, P., Erickson, A. K., Her, J. H., Shabanowitz, J., et al. (1991). Identification of the regulatory phosphorylation sites in pp42/mitogen-activated protein kinase (MAP kinase). EMBO J. 10, 885-892.
Pecher, P., Eschen-Lippold, L., Herklotz, S., Kuhle, K., Naumann, K., Bethke, G., et al. (2014). The Arabidopsis thaliana mitogen-activated protein kinases MPK3 and MPK6 target a subclass of 'VQ-motif'-containing proteins to regulate immune responses. New Phytol. 203, 592-606. doi: 10.1111/nph.12817

Pérez-Salamó, I., Papdi, C., Rigó, G., Zsigmond, L., Vilela, B., Lumbreras, V., et al. (2014). The heat shock factor A4A confers salt tolerance and is regulated by oxidative stress and the mitogen-activated protein kinases MPK3 and MPK6. Plant Physiol. 165, 319-334. doi: 10.1104/pp.114.237891

Persak, H., and Pitzschke, A. (2013). Tight interconnection and multi-level control of Arabidopsis MYB44 in MAPK cascade signalling. PLoS ONE 8:e57547. doi: 10.1371/journal.pone.0057547

Pitzschke, A., Datta, S., and Persak, H. (2014). Salt stress in Arabidopsis: lipid transfer protein AZI1 and its control by mitogen-activated protein kinase MPK3. Mol. Plant 7, 722-738. doi: 10.1093/mp/sst157

Pitzschke, A., Djamei, A., Teige, M., and Hirt, H. (2009). VIP1 response elements mediate mitogen-activated protein kinase 3-induced stress gene expression. Proc. Natl. Acad. Sci. U.S.A. 106, 18414-18419. doi: 10.1073/pnas.09055 99106

Popescu, S. C., Popescu, G. V., Bachan, S., Zhang, Z., Gerstein, M., Snyder, M., et al. (2009). MAPK target networks in Arabidopsis thaliana revealed using functional protein microarrays. Genes Dev. 23, 80-92. doi: $10.1101 /$ gad.1740009

Préstamo, G., Testillano, P. S., Vicente, O., González-Melendi, P., Coronado, M. J., Wilson, C., et al. (1999). Ultrastructural distribution of a MAP kinase and transcripts in quiescent and cycling plant cells and pollen grains. J. Cell Sci. 112 (Pt 7), 1065-1076.

Raghuram, B., Sheikh, A. H., Rustagi, Y., and Sinha, A. K. (2015). MicroRNA biogenesis factor DRB1 is a phosphorylation target of mitogen activated protein kinase MPK3 in both rice and Arabidopsis. FEBS J. 282, 521-536. doi: $10.1111 /$ febs.13159

Ranf, S., Eschen-Lippold, L., Pecher, P., Lee, J., and Scheel, D. (2011). Interplay between calcium signalling and early signalling elements during defence responses to microbe- or damage-associated molecular patterns. Plant J. 68, 100-113. doi: 10.1111/j.1365-313X.2011.04671.x

Rayapuram, N., Bigeard, J., Alhoraibi, H., Bonhomme, L., Hesse, A.-M., Vinh, J., et al. (2017). Quantitative phosphoproteomic analysis reveals shared and specific targets of Arabidopsis MPK3, MPK4 and MPK6. Mol. Cell. Proteomics 17:mcp.RA117.000135. doi: 10.1074/mcp.RA117.000135

Robinson, M. J., Stippec, S. A., Goldsmith, E., White, M. A., and Cobb, M. H. (1998). A constitutively active and nuclear form of the MAP kinase ERK2 is sufficient for neurite outgrowth and cell transformation. Curr. Biol. 8, 1141-1150. doi: 10.1016/S0960-9822(07)00485-X

Rodríguez, J., and Crespo, P. (2011). Working without kinase activity: phosphotransfer-independent functions of extracellular signal-regulated kinases. Sci. Signal. 4:re3. doi: 10.1126/scisignal.2002324

Rodriguez, M. C., Petersen, M., and Mundy, J. (2010). Mitogen-activated protein kinase signaling in plants. Annu. Rev. Plant Biol. 61, 621-649. doi: 10.1146/annurev-arplant-042809-112252

Roux, M. E., Rasmussen, M. W., Palma, K., Lolle, S., Regué, A. M., Bethke, G., et al. (2015). The mRNA decay factor PAT1 functions in a pathway including MAP kinase 4 and immune receptor SUMM2. EMBO J. 34, 593-608. doi: 10.15252/embj.201488645

Ryu, H., Laffont, C., Frugier, F., and Hwang, I. (2017). MAP kinase-mediated negative regulation of symbiotic nodule formation in Medicago truncatula. Mol. Cells 40, 17-23. doi: 10.14348/molcells.2017.2211

Salvador, J. M., Mittelstadt, P. R., Guszczynski, T., Copeland, T. D., Yamaguchi, H., Appella, E., et al. (2005). Alternative p38 activation pathway mediated by $\mathrm{T}$ cell receptor-proximal tyrosine kinases. Nat. Immunol. 6, 390-395. doi: $10.1038 /$ ni1 177

Samaj, J., Ovecka, M., Hlavacka, A., Lecourieux, F., Meskiene, I., Lichtscheidl, I., et al. (2002). Involvement of the mitogen-activated protein kinase SIMK in regulation of root hair tip growth. EMBO J. 21, 3296-3306. doi: 10.1093/emboj/cdf349

Šamajová , O., Komis, G., and Šamaj, J. (2012). Emerging topics in the cell biology of mitogen-activated protein kinases. Trends Plant Sci. 18, 140-148. doi: 10.1016/j.tplants.2012.11.004

Sasabe, M., Soyano, T., Takahashi, Y., Sonobe, S., Igarashi, H., Itoh, T. J., et al. (2006). Phosphorylation of NtMAP65-1 by a MAP kinase down-regulates its 
activity of microtubule bundling and stimulates progression of cytokinesis of tobacco cells. Genes Dev. 20, 1004-1014. doi: 10.1101/gad.1408106

Schweighofer, A., Kazanaviciute, V., Scheikl, E., Teige, M., Doczi, R., Hirt, H., et al. (2007). The PP2C-type phosphatase AP2C1, which negatively regulates MPK4 and MPK6, modulates innate immunity, jasmonic acid, and ethylene levels in Arabidopsis. Plant Cell 19, 2213-2224. doi: 10.1105/tpc.106. 049585

Serber, Z., and Ferrell, J. E. Jr. (2007). Tuning bulk electrostatics to regulate protein function. Cell 128, 441-444. doi: 10.1016/j.cell.2007.01.018

Sethi, V., Raghuram, B., Sinha, A. K., and Chattopadhyay, S. (2014). A mitogenactivated protein kinase cascade module, MKK3-MPK6 and MYC2, is involved in blue light-mediated seedling development in Arabidopsis. Plant Cell. 26, 3343-3357. doi: $10.1105 /$ tpc.114.128702

Sheikh, A. H., Eschen-Lippold, L., Pecher, P., Hoehenwarter, W., Sinha, A. K., Scheel, D., et al. (2016). Regulation of WRKY46 transcription factor function by mitogen-activated protein kinases in Arabidopsis thaliana. Front. Plant Sci. 7:61. doi: $10.3389 /$ fpls.2016.00061

Sheikh, A. H., Raghuram, B., Jalmi, S. K., Wankhede, D. P., Singh, P., and Sinha, A. K. (2013). Interaction between two rice mitogen activated protein kinases and its possible role in plant defense. BMC Plant Biol. 13:121. doi: 10.1186/1471-2229-13-121

Shen, H., Liu, C., Zhang, Y., Meng, X., Zhou, X., Chu, C., et al. (2012). OsWRKY30 is activated by MAP kinases to confer drought tolerance in rice. Plant Mol. Biol. 80, 241-253. doi: 10.1007/s11103-012-9941-y

Shen, X., Yuan, B., Liu, H., Li, X., Xu, C., and Wang, S. (2010). Opposite functions of a rice mitogen-activated protein kinase during the process of resistance against Xanthomonas oryzae. Plant J. 64, 86-99. doi: 10.1111/j.1365-313X.2010.04306.x

Sheridan, D. L., Kong, Y., Parker, S. A., Dalby, K. N., and Turk, B. E. (2008). Substrate discrimination among mitogen-activated protein kinases through distinct docking sequence motifs. J. Biol. Chem. 283, 19511-19520. doi: 10.1074/jbc.M801074200

Shi, J., An, H.-L., Zhang, L., Gao, Z., and Guo, X.-Q. (2010). GhMPK7, a novel multiple stress-responsive cotton group C MAPK gene, has a role in broad spectrum disease resistance and plant development. Plant Mol. Biol. 74, 1-17. doi: 10.1007/s11103-010-9661-0

Shi, J., Zhang, L., An, H., Wu, C., and Guo, X. (2011). GhMPK16, a novel stressresponsive group D MAPK gene from cotton, is involved in disease resistance and drought sensitivity. BMC Mol. Biol. 12:22. doi: 10.1186/1471-2199-12-22

Shin, H.-Y., You, M. K., Jeung, J. U., and Shin, J. S. (2014). OsMPK3 is a TEY-type rice MAPK in Group C and phosphorylates OsbHLH65, a transcription factor binding to the E-box element. Plant Cell Rep. 33, 1343-1353. doi: 10.1007/s00299-014-1620-9

Singh, P., and Sinha, A. K. (2016). A positive feedback loop governed by SUB1A1 interaction with MITOGEN-ACTIVATED PROTEIN KINASE3 imparts submergence tolerance in rice. Plant Cell 28, 1127-1143. doi: $10.1105 /$ tpc. 15.01001

Smertenko, A. P., Chang, H. Y., Sonobe, S., Fenyk, S. I., Weingartner, M., Bögre, L., et al. (2006). Control of the AtMAP65-1 interaction with microtubules through the cell cycle. J. Cell Sci. 119, 3227-3237. doi: 10.1242/jcs. 03051

Sörensson, C., Lenman, M., Veide-Vilg, J., Schopper, S., Ljungdahl, T., Grötli, M., et al. (2012). Determination of primary sequence specificity of Arabidopsis MAPKs MPK3 and MPK6 leads to identification of new substrates. Biochem. J. 446, 271-278. doi: 10.1042/BJ20111809

Suarez-Rodriguez, M. C., Adams-Phillips, L., Liu, Y., Wang, H., Su, S. H., Jester, P. J., et al. (2007). MEKK1 is required for flg22-induced MPK4 activation in Arabidopsis plants. Plant Physiol. 143, 661-669. doi: 10.1104/pp.106. 091389

Suzuki, T., Matsushima, C., Nishimura, S., Higashiyama, T., Sasabe, M., and Machida, Y. (2016). Identification of phosphoinositide-binding protein PATELLIN2 as a substrate of arabidopsis MPK4 MAP kinase during septum formation in cytokinesis. Plant Cell Physiol. 57, 1744-1755. doi: $10.1093 /$ pcp/pcw098

Takahashi, F., Mizoguchi, T., Yoshida, R., Ichimura, K., and Shinozaki, K. (2011). Calmodulin-dependent activation of MAP kinase for ROS homeostasis in Arabidopsis. Mol. Cell 41, 649-660. doi: 10.1016/j.molcel.2011.02.029

Tamura, K., and Hara-Nishimura, I. (2013). The molecular architecture of the plant nuclear pore complex. J. Exp. Bot. 64, 823-832. doi: 10.1093/jxb/ers258
Tanoue, T., Adachi, M., Moriguchi, T., and Nishida, E. (2000). A conserved docking motif in MAP kinases common to substrates, activators and regulators. Nat. Cell Biol. 2, 110-116. doi: 10.1038/35000065

Teige, M., Scheikl, E., Eulgem, T., Döczi, R., Ichimura, K., Shinozaki, K., et al. (2004). The MKK2 pathway mediates cold and salt stress signaling in Arabidopsis. Mol. Cell 15, 141-152. doi: 10.1016/j.molcel.2004.06.023

The Arabidopsis-Genome-Initiative. (2000). Analysis of the genome sequence of the flowering plant Arabidopsis thaliana. Nature 408, 796-815. doi: $10.1038 / 35048692$

Tsuda, K., Mine, A., Bethke, G., Igarashi, D., Botanga, C. J., Tsuda, Y., et al. (2013). Dual regulation of gene expression mediated by extended MAPK activation and salicylic acid contributes to robust innate immunity in Arabidopsis thaliana. PLoS Genet. 9:e1004015. doi: 10.1371/journal.pgen.1004015

Ubersax, J. A., and Ferrell, J. E. Jr. (2007). Mechanisms of specificity in protein phosphorylation. Nat. Rev. Mol. Cell Biol. 8, 530-541. doi: 10.1038/nrm2203

Umbrasaite, J., Schweighofer, A., Kazanaviciute, V., Magyar, Z., Ayatollahi, Z., Unterwurzacher, V., et al. (2010). MAPK phosphatase AP2C3 induces ectopic proliferation of epidermal cells leading to stomata development in Arabidopsis. PLoS ONE 5:e15357. doi: 10.1371/journal.pone.0015357

Underwood, W., Zhang, S., and He, S. Y. (2007). The Pseudomonas syringae type III effector tyrosine phosphatase HopAO1 suppresses innate immunity in Arabidopsis thaliana. Plant J. 52, 658-672. doi: $10.1111 / \mathrm{j} .1365-313 \mathrm{X} .2007 .03262 . \mathrm{x}$

Venter, J. C., Adams, M. D., Myers, E. W., Li, P. W., Mural, R. J., Sutton, G. G., et al. (2001). The sequence of the human genome. Science 291, 1304-1351. doi: 10.1126/science. 1058040

Wang, C., He, X., Li, Y., Wang, L., Guo, X., and Guo, X. (2017). The cotton MAPK kinase GhMPK20 negatively regulates resistance to Fusarium oxysporum by mediating the MKK4-MPK20-WRKY40 cascade. Mol. Plant Pathol. doi: 10.1111/mpp.12635. [Epub ahead of print].

Wang, D., Harper, J. F., and Gribskov, M. (2003). Systematic trans-genomic comparison of protein kinases between Arabidopsis and Saccharomyces cerevisiae. Plant Physiol. 132, 2152-2165. doi: 10.1104/pp.103.021485

Wang, F., Shang, Y., Fan, B., Yu, J. Q., and Chen, Z. (2014). Arabidopsis LIP5, a positive regulator of multivesicular body biogenesis, is a critical target of pathogen-responsive mapk cascade in plant basal defense. PLoS Pathog. 10:e1004243. doi: 10.1371/journal.ppat.1004243

Wang, F., Wang, C., Yan, Y., Jia, H., and Guo, X. (2016). Overexpression of cotton GhMPK11 decreases disease resistance through the gibberellin signaling pathway in transgenic Nicotiana benthamiana. Front. Plant Sci. 7:689. doi: $10.3389 /$ fpls.2016.00689

Wang, F., Yang, Y., Wang, Z., Zhou, J., Fan, B., and Chen, Z. (2015). A critical role of lyst-interacting protein5, a positive regulator of multivesicular body biogenesis, in plant responses to heat and salt stresses. Plant Physiol. 169, 497-511. doi: 10.1104/pp. 15.00518

Wang, J., Ding, H., Zhang, A., Ma, F., Cao, J., and Jiang, M. (2010). A novel mitogen-activated protein kinase gene in maize (Zea mays), ZmMPK3, is involved in response to diverse environmental cues. J. Integr. Plant Biol. 52, 442-452. doi: 10.1111/j.1744-7909.2010.00906.x

Wang, P., Du, Y., Zhao, X., Miao, Y., and Song, C.-P. (2013). The MPK6-ERF6ROS-responsive cis-acting Element7/GCC box complex modulates oxidative gene transcription and the oxidative response in Arabidopsis. Plant Physiol. 161, 1392-1408. doi: 10.1104/pp.112.210724

Whitehurst, A., Cobb, M. H., and White, M. A. (2004). Stimulus-coupled spatial restriction of extracellular signal-regulated kinase $1 / 2$ activity contributes to the specificity of signal-response pathways. Mol. Cell. Biol. 24, 10145-10150. doi: 10.1128/MCB.24.23.10145-10150.2004

Xie, K., Chen, J., Wang, Q., and Yang, Y. (2014). Direct Phosphorylation and activation of a mitogen-activated protein kinase by a calcium-dependent protein kinase in rice. Plant Cell 26, 3077-3089. doi: 10.1105/tpc.114.126441

Xin, X., Chen, W., Wang, B., Zhu, F., Li, Y., Yang, H., et al. (2018). Arabidopsis MKK10-MPK6 mediates red-light-regulated opening of seedling cotyledons through phosphorylation of PIF3. J. Exp. Bot. 69, 423-439. doi: $10.1093 /$ jxb/erx418

Xu, J., Meng, J., Meng, X., Zhao, Y., Liu, J., Sun, T., et al. (2016). Pathogen-responsive MPK3 and MPK6 reprogram the biosynthesis of indole glucosinolates and their derivatives in Arabidopsis immunity. Plant Cell 28, 1144-1162. doi: $10.1105 /$ tpc. 15.00871 
Yadav, V., Mallappa, C., Gangappa, S. N., Bhatia, S., and Chattopadhyay, S. (2005). A basic helix-loop-helix transcription factor in Arabidopsis, MYC2, acts as a repressor of blue light-mediated photomorphogenic growth. Plant Cell 17, 1953-1966. doi: $10.1105 /$ tpc. 105.032060

Yang, T., Shad Ali, G., Yang, L., Du, L., Reddy, A. S., and Poovaiah, B. W. (2010), Calcium/calmodulin-regulated receptor-like kinase CRLK1 interacts with MEKK1 in plants. Plant Signal. Behav. 5, 991-994. doi: 10.4161/psb.5.8.12225

Yap, Y.-K., Kodama, Y., Waller, F., Chung, K. M., Ueda, H., Nakamura, K., et al. (2005). Activation of a novel transcription factor through phosphorylation by wipk, a wound-induced mitogen-activated protein kinase in tobacco plants. Plant Physiol. 139, 127-137. doi: 10.1104/pp.105.065656

Yoo, S. D., Cho, Y. H., Tena, G., Xiong, Y., and Sheen, J. (2008). Dual control of nuclear EIN3 by bifurcate MAPK cascades in C2H4 signalling. Nature 451, 789-795. doi: 10.1038/nature06543

Zaïdi, I., Ebel, C., Touzri, M., Herzog, E., Evrard, J.-L., Schmit, A. C., et al. (2010). TMKP1 is a novel wheat stress responsive MAP kinase phosphatase localized in the nucleus. Plant Mol. Biol. 73, 325-338. doi: 10.1007/s11103-010-9617-4

Zeke, A., Lukács, M., Lim, W. A., and Reményi, A. (2009). Scaffolds: interaction platforms for cellular signalling circuits. Trends Cell Biol. 19, 364-374. doi: 10.1016/j.tcb.2009.05.007

Zhang, L., Xi, D., Li, S., Gao, Z., Zhao, S., Shi, J., et al. (2011). A cotton group C MAP kinase gene, GhMPK2, positively regulates salt and drought tolerance in tobacco. Plant Mol. Biol. 77, 17-31. doi: 10.1007/s11103-011-9788-7

Zhang, Y., Guo, X., and Dong, J. (2016). Phosphorylation of the polarity protein BASL differentiates asymmetric cell fate through MAPKs and SPCH. Curr. Biol. 26, 2957-2965. doi: 10.1016/j.cub.2016.08.066

Zhang, Y., Wang, P., Shao, W., Zhu, J.-K., and Dong, J. (2015). The BASL polarity protein controls a MAPK signaling feedback loop in asymmetric cell division. Dev. Cell 33, 136-149. doi: 10.1016/j.devcel.2015 02.022

Zhao, C., Nie, H., Shen, Q., Zhang, S., Lukowitz, W., and Tang, D. (2014). EDR1 physically interacts with MKK4/MKK5 and negatively regulates a MAP kinase cascade to modulate plant innate immunity. PLoS Genet. 10:e1004389. doi: 10.1371/journal.pgen.1004389

Zhao, C., Wang, P., Si, T., Hsu, C.-C., Wang, L., Zayed, O., et al. (2017). MAP kinase cascades regulate the cold response by modulating ICE1 protein stability. Dev. Cell 43, 618.e5-629.e5. doi: 10.1016/j.devcel.2017.09.024

Zipfel, C., Kunze, G., Chinchilla, D., Caniard, A., Jones, J. D., Boller, T., et al. (2006). Perception of the bacterial PAMP EF-Tu by the receptor EFR restricts Agrobacterium-mediated transformation. Cell 125, 749-760. doi: 10.1016/j.cell.2006.03.037

Zong, X., Li, D. P, Gu, L., Li, D. Q., Liu, L., and Hu, X. L. (2009). Abscisic acid and hydrogen peroxide induce a novel maize group C MAP kinase gene, ZmMPK7, which is responsible for the removal of reactive oxygen species. Planta 229, 485-495. doi: 10.1007/s00425-008-0848-4

Conflict of Interest Statement: The authors declare that the research was conducted in the absence of any commercial or financial relationships that could be construed as a potential conflict of interest.

Copyright () 2018 Bigeard and Hirt. This is an open-access article distributed under the terms of the Creative Commons Attribution License (CC BY). The use, distribution or reproduction in other forums is permitted, provided the original author(s) and the copyright owner are credited and that the original publication in this journal is cited, in accordance with accepted academic practice. No use, distribution or reproduction is permitted which does not comply with these terms. 